\title{
Investment and usage of new technologies: evidence from a shared ATM network
}

\author{
Stijn Ferrari, Frank Verboven, Hans Degryse*
}

March 2009

\begin{abstract}
The success of new technologies does not only depend on the firms' investment incentives, but often also on the consumers' usage decisions. This paper studies investment and usage in a shared ATM network. Inefficiencies may arise because banks coordinate their investment decisions and consumers may not make proper use of the cost-saving ATM network because of regulated retail fees. We develop an empirical model of ATM investment (or entry) and cash withdrawal demand. We find that banks substantially underinvested in the shared ATM network, in contrast with findings for the U.S., showing strategic overinvestment under partially incompatible networks. Furthermore, we find that consumer usage of the available ATM network is too low, because of the zero retail fees for cash withdrawals at branches. A direct promotion of investment can improve welfare, but the introduction of retail fees on cash withdrawals at branches would be more effective, even if this does not encourage investment per se.
\end{abstract}

JEL Numbers: G21, L10, L50, L89

Keywords: investment, new technologies, ATMs, network industries, empirical entry models.

*Stijn Ferrari: Catholic University of Leuven. Email: Stijn.Ferrari@econ.kuleuven.be. Frank Verboven: Catholic University of Leuven and C.E.P.R. (London). E-mail: Frank.Verboven@econ.kuleuven.be. Hans Degryse: CentER, EBC, TILEC, Tilburg University. Email: H.Degryse@uvt.nl. We thank Lapo Filistrucchi, Xavier Freixas, Christa Hainz, Frode Steen, Javier Suarez, Patrick Waelbroeck, and especially two referees and the editor for very useful comments. We also thank seminar participants at CREST, K.U.Leuven, U.C.L, TILEC, Harvard/MIT, Stern and Wharton, and conference participants at EARIE 2007, IDEI/Bruegel 2007, Telecom Paris-ENST 2007, CEPR-ESSFM Gerzensee 2007, CESIfo Applied Micro 2008, and C.E.P.R. Applied IO 2008. We are also grateful to Joost Martens for support in obtaining the data on the shared ATM network. Hans Degryse is a CESIfo research fellow and holds the TILEC-AFM Chair on financial market regulation. 
The incentives to invest in new technologies are not necessarily in line with social welfare. On the one hand, firms may underinvest because they are not able to appropriate all consumer surplus. On the other hand, they may strategically overinvest because they do not account for the business stealing effects on their competitors. While the reasons for underand overinvestment in new technologies have become reasonably well-understood, ${ }^{1}$ empirical evidence remains limited. Furthermore, the focus on investment incentives often provides an incomplete picture; in many settings it is also essential to understand how consumers respond and are willing to use the new technology. While the joint importance of investment and usage of new technologies has been stressed by policy makers, it has received little attention in academic research. ${ }^{2}$

Automated teller machines (ATMs) provide a particularly interesting case to study the interplay between the firms' investment and the consumers' usage decisions of a new technology. The technology became available in the seventies and provided important opportunities to the banks to save on the high variable costs from branch transactions by inducing consumers to substitute to lower cost ATM transactions. Since substantial fixed investment costs were required to create sufficient geographical coverage, banks quickly joined forces to build large compatible, or shared, ATM networks. By the early nineties many European countries and U.S. states effectively had a single shared ATM network, accessible to most consumers. In the U.S. this trend reversed with the introduction of surcharges around 1996. The resulting partial incompatibility between ATMs created the possibility of strategic overinvestment in ATMs, as has become well-documented in several recent U.S. studies. ${ }^{3}$ In contrast, very little is known about potential underinvestment in compatible or shared ATM networks, which remained common in many European countries until recently. Furthermore, even less is known on how effective these investments in infrastructure have been in inducing consumers to substitute and use the new cost-saving technology.

This paper aims to shed light on both the firms' investment incentives and the consumers' usage decisions in a shared ATM network. We consider the case of Belgium, which is representative for many other European countries. Until recently all banks jointly owned a

\footnotetext{
${ }^{1}$ See in particular Arrow (1962), Gilbert and Newbery (1982) and many related contributions regarding the role of market structure on the incentives to invest in new technologies.

${ }^{2}$ For example, the most recent OECD (2007) Communications Outlook uses both infrastructure investment and consumer usage criteria in evaluating the performance of new information and communication technologies such as broadband. In contrast, the economics literature on technology adoption tends to treat firm investment and consumer adoption separately, as illustrated by Stoneman's (2002) review of the literature.

${ }^{3}$ See, for example, Gowrisankaran and Krainer (2007), Hannan and Borzekowski (2007), Ishii (2005) and several other studies, as reviewed below.
} 
single shared ATM network and coordinated their ATM investment decisions. At the same time, regulation prevented the banks from charging retail fees for cash withdrawals both at their own branches and at their shared ATMs. This environment provides an interesting real world counterfactual to the recent U.S. case with partially incompatible ATM networks and strategic investment incentives. In our case, ATM investment was not driven by revenue or strategic considerations. It was instead essentially motivated by a variable cost-saving incentive, i.e. the prospect that increased ATM availability would induce consumers to substitute out of high variable cost branch transactions towards low variable cost ATM transactions. We ask the following two related questions. First, to which extent did this environment of coordinated investment lead to underinvestment in the ATM network? Second, to which extent did the zero retail fees on cash withdrawals provide the wrong incentives to consumers and did it induce them to use branches too often relative to the available ATMs? To address these questions, we assess how a direct promotion of investment (through subsidies or other means) and the introduction of retail fees can contribute to improving social welfare.

We develop an empirical model of consumer cash withdrawal demand and coordinated ATM investment in local markets. Consumers' demand for branch and ATM cash withdrawals depends on local ATM availability. The banks' ATM investment decisions involve a trade-off between variable transaction cost savings and additional fixed costs from expanding the network. The model generates the following insights. First, it measures how increased ATM availability induces consumers to substitute out of branch to ATM cash withdrawals. Second, it allows us to infer the relative importance of fixed costs per ATM and the variable cost savings from increased ATM usage. To estimate the model we have collected a unique data set on ATM cash withdrawal transactions and the number of ATMs, covering the entire network across Belgian local markets.

We find evidence of substantial underinvestment in the provision of ATMs: the total number of ATMs is only about half of the socially optimal number and the number of markets without an ATM is three times higher than in the social optimum. These findings stem from the fact that the coordinating banks cannot appropriate consumer surplus (in the form of improved convenience from increased ATM availability) and do not have strategic motives to invest. However, while the limited ATM investments and especially the perceived lack of geographic coverage have been highly sensitive political issues, this is only part of the welfare story. We find that the welfare losses also stem from the fact that cash withdrawal fees on both branches and ATMs have been regulated to zero, so that consumers make too limited use of the existing ATM network. To achieve the maximum welfare gains the direct promotion of ATM investment (through subsidies or other means) should be combined with the introduction of retail fees for cash withdrawals at branches. If both policies cannot be 
combined, a second-best "fees-only" policy is more effective than an alternative "subsidiesonly" policy that directly promotes ATM investment while keeping fees regulated to zero. This is because a fees-only policy also accomplishes desirable cost-saving substitution to ATMs without requiring large additional fixed cost investments in a dense ATM network. At a more general level, our findings imply that economic analysis and policy may often be too pre-occupied with stimulating investment per se, and should be more concerned with providing the correct price incentives to achieve an efficient usage of the cost-reducing investments.

Our paper contributes to the general interest question on investment and usage of new technologies. Internet broadband and environmentally friendlier gasoline engines are two other examples where the success of a new technology depends on both the (geographic) investment decisions by firms and on the adoption decisions by users. We discuss these examples and the role of regulation in our concluding section.

Our paper also contributes to the growing empirical literature on ATMs. Most of this literature has been motivated by the recent move in the U.S. to partial incompatibility after the introduction of surcharges. In particular, Gowrisankaran and Krainer (2007) and Ishii (2005) develop structural models of ATM investment, enabling a welfare analysis. ${ }^{4}$ They focus on respectively the stand-alone revenue motives and the strategic motives for investing in ATMs. The presence of strategic considerations indicates a tendency towards overinvestment in ATMs relative to the social optimum. Both studies do not take into account the cost-saving incentives for ATM investment. In contrast, based on a unique data set on cash withdrawals, we focus on this pure cost-saving incentive: in a market with full compatibility and coordinated investment, we find evidence of substantial underinvestment in ATM network coverage, combined with an insufficient usage of the existing investments due to incorrect price incentives. While several studies have measured the variable cost savings from ATM cash withdrawals based on accounting or processing time information, ${ }^{5}$ no work has attempted to integrate this in a model to study the firms' investment incentives and consumers' usage responses.

From a methodological perspective our empirical model of ATM investment closely relates to the empirical entry literature. Bresnahan and Reiss (1990, 1991) and Berry (1992) introduced models of free entry. Berry and Waldfogel (1999) added a demand side to the

\footnotetext{
${ }^{4}$ Other empirical contributions on the effects of greater incompatibility on ATM investment include Knittel and Stango $(2006,2008)$ and Hannan and Borzekowski (2007). Theoretical contributions on ATM deployment and efficiency include Matutes and Padilla (1994), Bernhardt and Massoud (2005), Donze and Dubec (2006, 2008) and Chioveanu et al. (2008).

${ }^{5}$ See for example, Felgran (1984), Humphrey et al. (2003), and other references in section I A.
} 
free entry model enabling them to draw inferences on fixed costs. Ishii (2005) models ATM investment and deposit demand sequentially, using Pakes et al.'s (2006) moment inequalities method for the investment part of the model. In contrast with Berry and Waldfogel (1999) and Ishii (2005) we consider coordinated investment. Furthermore, we allow ATM demand and investment to be simultaneously determined, i.e. we account for the fact that they may depend on common unobserved local market characteristics. Intuitively, banks tend to invest especially in markets where they expect a high ATM demand. We therefore account for both selection and endogeneity issues in measuring the causal impact of ATM investment on ATM demand.

The paper is organized as follows. Section I discusses the relevant industry background in an international context and takes a first look at our data set. Section II presents the model of coordinated investment, and compares it with socially optimal investment. Sections III, IV and V discuss the econometric specification, the empirical results, and the policy counterfactuals. Section VI presents a robustness analysis from three extensions of the model, and Section VII concludes.

\section{Industry background and data set}

We first discuss the industry background motivating our econometric model, showing that the shared network in Belgium is representative for many other European countries and provides an interesting contrast with the U.S., especially after the introduction of surcharges. We then have a first look at the data set.

\section{A. Industry background}

International context Banks traditionally used their branch networks to provide cash withdrawal services to their customers. In the late sixties and the early seventies the first ATMs emerged, providing the banks with opportunities to reduce labour costs at their branches. While a first look may suggest that ATM networks developed quite differently across countries, a closer study reveals several important common features. In Appendix $\mathrm{B}$ we review the evolution in 16 European countries along the following dimensions: the number of shared ATM networks, ownership and coordination, and retail fee practices.

Table 1 summarizes our findings. First, while the industry often started with several competing networks, almost all countries had moved to a single shared ATM network by the early nineties. Second, in eight countries there was common ownership of the shared network and coordination of investment decisions. In the other eight countries there was no 
common ownership, but in some countries (France, Italy) investment was still coordinated. Third, retail fees were typically zero or very low (RBR (2005)). As summarized in World Payments Reports (WPR (2006), p. 45), "in most countries there is no charge on ATM cash withdrawals, or on cash withdrawals via a bank branch - the most costly type of withdrawal for banks". ${ }^{6}$ Regarding ATMs, on-us fees (charged by the customer's bank for cash withdrawals at the own bank) were almost always zero. Foreign fees (charged by the customer's bank for cash withdrawals at other banks) were also zero or small, with the exception of Germany, Italy, Spain and the U.K., where foreign fees applied to banks from different banking groups. Surcharges (charged by the owner of the ATM) did not exist, except in the U.K.

By the mid-nineties the following eight European countries therefore had a single shared ATM network, with common ownership and coordination, and no or very low retail fees: Austria, Belgium, Denmark, Finland, Greece, Luxemburg, the Netherlands and Portugal. France also resembled this situation, although there was no common ownership of the network. In most other countries there was neither common ownership nor coordination, and foreign fees could be relatively high (depending on the bank) in Germany, Italy, Spain and the U.K.

Until 1996 the evolution in the U.S. was similar to this latter group of countries. In most U.S. states the many smaller regional networks were quickly interconnected and consolidated into shared networks. There was typically no common ownership, though exceptions existed; see McAndrews and Rob (1996) for an overview, and Carlton and Frankel (1995) for a discussion of a merged monopoly regional network in Chicago. Finally, U.S. banks commonly charged foreign fees. After 1996, surcharges were introduced and the situation differed quite dramatically from all European countries except the U.K.

In sum, the shared network in Belgium was similar to that in many other European countries. It differed, however, from Germany, Italy, Spain, the U.K. and most U.S. states, where there was no common ownership and coordination of investment and where foreign fees often existed. Against this background, we now discuss the network in Belgium in more detail.

The evolution to a shared ATM network In the late seventies Belgian banks created two competing ATM networks. Consumers could withdraw cash from any ATM of their own network, but had no access to the competing network. Because of cost considerations and

\footnotetext{
${ }^{6}$ Consumer organizations have been quite successful in lobbying at the political level, and in using the press to convey their plea for free payments. A French bank willing to introduce fees for cheques, for example, was roundly criticized and public pressure induced it to remove any cost-based pricing (WPR (2005)).
} 
public pressure to increase user convenience the two networks were made compatible in 1987, enabling all debit card holders to withdraw cash from ATMs of either network. In 1990, the two networks merged completely to create a common network operator, Banksys, co-owned by all the banks. Banksys managed the shared ATM network and the emerging electronic services with debit cards. ${ }^{7}$

During 1990-2005, an ATM-committee within Banksys made the decisions to invest in additional ATMs, and replace or remove existing ones. This ATM-committee consisted of representatives of the larger banks, a representative of the smaller banks and a representative of the network operator. The committee decided on the number and location of ATMs for each local market. The ATMs were always installed at one of the banks' branches, hence never "off-premise" (e.g. in shopping malls). The banks had to bear the costs of the ATMs that were located at their branches, including the fixed investment and maintenance costs and the variable costs of cash withdrawals (e.g. refilling ATMs). There were a number of mechanisms to ensure cooperation among all banks. First, there was a mutual understanding that banks should host ATMs in proportion to their market shares. In practice, the banks' ATM market shares were indeed close to and strongly correlated with their branch or deposit market shares. ${ }^{8}$ Second, banks received compensation for the ATM services through costbased interchange fees.

Figure 1 shows the evolution of the total number of ATMs in Belgium since 1979. The ATM network has grown nearly linearly during the eighties to reach maturity in the early nineties; during that time the size of the banks' branch networks remained more or less constant. Our data set covers a cross-section of local markets in 1994. This year is wellsuited for studying ATM investment and demand. First, Figure 1 shows that 1994 represents a mature long-term situation, making it reasonable to abstract from dynamic considerations. Second, in 1994 consumers still made only limited use of electronic payment services and of incompatible private ATMs, installed within the banks' own branches. ${ }^{9}$

\footnotetext{
${ }^{7}$ As in some other countries, there was one other very small network, Postomat, accessible only to the customers of the Belgian Postal Bank. This network joined forces with Banksys in 2000.

${ }^{8}$ In 1994, the seven large banks were ASLK, Generale Bank, Gemeentekrediet, BBL, Kredietbank, Cera, and BACOB. According to the Belgian Banking Federation, Belgische Vereniging van Banken, B.V.B. (1994b, 1995), they had a nation-wide presence and market shares in terms of branches (deposits) of respectively 15 (12), 14 (13), 12 (15), 12 (10), $10(10), 12(5)$ and 8 (5) percent. Their market shares in the ATM network were respectively $21,21,16,13,9,5$ and 7 percent. The correlation between the ATM and branch market shares amounted to 0.79 across banks and regions. Similar correlations hold at a more local level (10 provinces).

${ }^{9}$ The incompatible private ATMs were exclusively for the bank's own customers, allowing for cash withdrawals and other traditional branch transactions, such as the ordering of documents and the transfering of funds. In 1994, less than one fifth of the branches were equipped with such an incompatible private ATM,
} 
Retail fees and costs of cash withdrawals Government regulation in Belgium has for a long time completely prevented the banks from charging retail fees for any payment related services, including cash withdrawals at branches or ATMs. Decreasing margins following intensified competition, a drop in the interbanking rates, and public demand for more transparency increased the banks' needs for charging retail fees. Intensive lobbying eventually resulted in stepwise liberalizations in 1991 and 1993, enabling the banks to charge variable retail fees for cash withdrawal services. In practice, however, a universal service obligation kept the variable fees equal to zero until the late nineties. ${ }^{10}$ In principle, banks could discourage branch cash withdrawals through other means than fees, for example by raising queues at tellers. In practice, branches are small and have no separate tellers for cash withdrawals, so such a policy would also reduce the quality of other services at the branches. ${ }^{11}$ Alternatively, banks could consider to discourage branch transactions by introducing "ATM only" accounts or other subsidies, but they did not follow these practices. ${ }^{12}$

The absence of retail fees does clearly not reflect the banks' costs. Several studies estimated the variable costs for cash withdrawal services based on accounting information or processing time per transaction. These studies find that variable costs are considerably higher at branches than at ATMs. For the U.S., Berger (1985) and Humphrey (1994) find that the variable costs are about twice as high at branches than at ATMs; Kimball and Gregor (1995) estimate a cost per transaction of $\$ 1.07$ at branches versus $\$ 0.27$ at ATMs; Fasig (2001) reports that transaction costs vary between $\$ 1-2$ at branches, compared with $\$ 0.15-0.50$ at ATMs. For Europe, we report the following transaction cost estimates for respectively branch and ATM withdrawals: U.K: $€ 0.96$ vs. $€ 0.19$; Norway: $€ 1.88$ vs. $€ 1.07$; Sweden: $€ 1.21$ vs. $€ 0.51$; Portugal: $€ 0.88$ vs. $€ 0.20 .{ }^{13}$ Introducing ATMs may thus gener-

and we will simply treat them as an integrated part of the banks' branch networks.

${ }^{10}$ The universal service obligation forced banks to offer a minimum amount of payment services, including cash withdrawals at branches or ATMs at a low cost. In practice, banks only charge a small annual fixed fee for payment services and no variable retail fees.

${ }^{11}$ According to B.V.B. (1994a), branches on average had about 3.5 employees in 1994, so separate tellers for cash withdrawals are uncommon. Since tellers spend more than three times of their services on other, non-routine services, raising queues would reduce overall quality of service and not be a good strategy to induce ATM usage. Branches could also reduce opening hourse to encourage usage of nearby ATMs, but this would again reduce quality of service, and according to a consumer organization, opening hours are fairly uniform across branches (Testaankoop (2003)).

${ }^{12}$ For an overview of practices in Belgium at that time, see financial newspaper De Tijd, 10 december 1996. "Tarifering banken bovenop basispakket steeg met 52 procent". More generally, European banks typically do not reward customers for using more efficient payment instruments (WPR (2005)).

${ }^{13}$ These estimates come from, respectively, Gow and Thomas (1997), Gresvik and Owre (2002), Guibourg and Segendorf (2004), and a Banco de Portugal (2007) report. 
ate important variable cost savings at branches. ${ }^{14}$ These should however be balanced against the fixed costs of investing and maintaining ATMs. According to the Belgian network operator Banksys, the fixed cost per ATM amounts to about $€ 2,300$ per month. This is similar to estimates quoted by Ishii (2005) for the U.S. ${ }^{15}$ We will come back to these cost estimates in our empirical analysis, where we will infer the ratio of fixed ATM costs over variable cost savings from our econometric model of ATM investment.

Summary Belgian banks have for a long time coordinated their investment decisions in the shared ATM network. The year 1994 is well-suited for an empirical analysis of ATM investment and demand since the network had matured and competing electronic payment services were still of limited importance. Banks charged no retail fees for cash withdrawal services, whether at incompatible branches or at shared ATMs. However, banks could realize potentially important variable cost savings from cash withdrawals at ATMs instead of branches, to be traded off against the fixed costs from setting-up and maintaining the shared ATM network. These observations will motivate our empirical model of coordinated investment, representative for many other European countries and providing an interesting contrast with the recent U.S. case.

\section{B. A first look at the data}

The data set Our main data set consists of ATM cash withdrawal demand and the number of ATMs for a cross-section of local markets in Belgium in 1994. The markets are defined by postal codes, which are part of administrative municipalities and typically consist of about one or two traditional towns. To reduce potential problems with overlapping markets, we focus on a subsample of 659 non-urban markets (defined as markets with a population density of less than 800 per $\mathrm{km}^{2}$ ), having on average about 8,700 inhabitants. But we also considered a robustness analysis based on the full sample of all 842 markets including the cities. For each market, we observe the total number of ATM cash withdrawals and their nominal monetary value, both expressed as 1994 monthly averages. In addition, we observe

\footnotetext{
${ }^{14}$ This does not mean that introducing ATMs should lead to fewer personnel at branches. In fact, branch employment has declined only slightly during the eighties and early nineties when ATMs were introduced. However, there was an important shift to high skilled labour from $68.2 \%$ in 1987 to $76.3 \%$ in 1997, indicating that banks could increasingly use their personnel on non-routine tasks in response to ATM and other technological developments (B.V.B. (1987, 1989, 1997)).

${ }^{15}$ Ishii (2005) quotes 2003 American Bankers' Association numbers, according to which the cost of buying an ATM machine is $\$ 50,000$, and annual maintenance cost is between $\$ 12,000$ and $\$ 15,000$. Using her five-year linear depreciation period this amounts to a monthly fixed cost of between $\$ 1,833$ and $\$ 2,083$.
} 
the number of shared ATMs, defined as the number of distinct ATM locations per market. We also collected data on the banks' branch locations in 1994, and on various demographic characteristics such as population size. ${ }^{16}$

Table 2 provides precise definitions of our variables, and Table 3 presents summary statistics for the cross-section of 659 non-urban markets, and the subsample of 310 markets with at least one ATM. The per capita number of ATM cash withdrawals $Q_{A}$ is on average 0.56 per month for all markets, and 0.78 for the markets with at least one ATM. ${ }^{17}$ The average value per cash withdrawal $V_{A} / Q_{A}$ is $€ 101$ (average across the markets with at least one ATM). The availability of ATMs across the local markets is rather limited. There are no ATMs in 349 out of 659 markets, and in those markets with at least one ATM the average number of ATMs $N$ is only 1.57 .

Consumers can also withdraw cash from their own bank branches rather than from the shared ATMs. We do not have data on branch cash withdrawals at the local market level; but at the national level, outside information shows that consumers make about 2.07 cash withdrawals per month. ${ }^{18}$ Hence, ATM usage is relatively limited: only about one third of the cash withdrawals take place at the shared ATMs and the remaining two-thirds are at the branches. Branch availability to consumers in need for cash can be measured since we observe the number of branches per market for each bank. Since branches of rival banks are not compatible, a crude aggregate measure of branch availability is the average number of branches per bank in each market. Table 3 shows that there are on average 0.86 branches per bank across all markets, and on average 1.25 branches per bank in the sample of markets with at least one shared ATM. Consumers thus tend to find about the same amount of branches of their own bank as shared ATMs within a local market.

The remaining variables are the market demographics. In our empirical analysis these may affect both ATM cash withdrawal demand and the profitability of investing in ATMs. The demographics include population (number of inhabitants per market), the market surface (in $\mathrm{km}^{2}$ ), the number of enterprises, the fraction of foreigners, the fraction of young (under the age of 18) and elderly (over the age of 65), the unemployment rate, and a dummy variable

\footnotetext{
${ }^{16}$ The data set on the ATMs was provided to us by the ATM network operator Banksys. The data on the branch locations is from B.V.B. (Belgian Banking Federation). The demographic characteristics were obtained from the N.I.S. (National Institute of Statistics), Ecodata (Federal Government Agency for Economics), and the R.S.Z. (the National Institute of Social Security).

${ }^{17}$ These averages become slightly larger when city markets are included, i.e. 0.80 for all markets, and 0.98 for the markets with at least one ATM.

${ }^{18}$ The outside information of 2.07 cash withdrawals per month is based on recent 2004 data at the national level on cash withdrawals (B.V.B. (2004)). Note that the government also used the number of 2 cash withdrawals per month in its universal service obligation proposal for the banks.
} 
for the region of Flanders (Dutch-speaking part of Belgium). Table 3 shows that several of the demographics may differ depending on whether the full sample or the subsample of markets with at least one ATM is considered. In particular, the average population size is 8,738 across all markets, but up to 13,445 in markets where banks invested in at least one ATM.

Preliminary relationships Table 4 shows the relationship between our main variables of interest, i.e. the per capita number of ATM cash withdrawals $Q_{A}$ and the number of shared ATMs, $N$. The average of $Q_{A}$ is 0.63 across markets with only one ATM and this gradually increases as $N$ increases, to reach an average of 1.13 in markets with 5 available ATMs. Table 4 also shows that the average value per cash withdrawal $V_{A} / Q_{A}$ decreases in $N$, but only weakly from $€ 102$ in markets with one ATM to $€ 98$ in markets with 5 ATMs.

To gain further insights in the relationship between ATM demand or usage and ATM availability, we estimate two simple OLS regressions, based on the sample of markets with at least one ATM. The first regression takes $\ln Q_{A}$ as the dependent variable and relates this to $\ln N$ and the $\log$ of the number of branches per bank, after controlling for the market demographics. In the second regression $\ln V_{A} / Q_{A}$ is the dependent variable, and includes the same explanatory variables. The regressions should be interpreted with care, as $\ln N$ may be correlated with the error term because of both sample selection and endogeneity issues: banks tend to invest in no or few ATMs in markets where they expect a low ATM demand, and vice versa.

Table 5 shows the results. We focus mainly on the regression for $\ln Q_{A}$ in the first part of the table. The elasticity of ATM cash withdrawal demand $Q_{A}$ with respect to the number of ATMs $N$ is 0.63 , which is positive and highly significant. This may describe a causal effect of ATM availability on demand or usage, or simply reflect the fact that banks invest in many ATMs when they expect high demand. Furthermore, the elasticity of ATM cash withdrawal demand with respect to the number of branches per bank is -0.51 . In absolute value this is not significantly different from the coefficient on the number of ATMs (p-value of 0.10). Hence, ATM usage increases by about the same amount when ATM availability increases as when per bank branch availability decreases. This indicates that consumers use ATMs as a substitute for branches to withdraw cash.

The second part of Table 5 shows the regression for $\ln V_{A} / Q_{A}$. The elasticity of the average value per cash withdrawal $V_{A} / Q_{A}$ with respect to the number of ATMs $N$ is negative and significant, but its magnitude is quite small (-0.03). Hence, while $Q_{A}$ increases substantially with ATM availability, $V_{A} / Q_{A}$ decreases only to a small extent. This suggests that the positive relationship between ATM withdrawals and availability is not due to the fact that 
consumers withdraw a lower value per transaction, but rather because they substitute out of cash withdrawals at branches.

We emphasize again that the regressions on ATM availability should be interpreted with care, because $N$ is an endogenous variable implying both selection and endogeneity issues with simple OLS estimation. The next sections develop and estimate a model of ATM demand and coordinated investment in ATMs that take these issues into account. This will enable us to obtain more reliable conclusions on the causal effect of ATM availability on demand, and to perform a welfare analysis regarding the optimality of ATM investment and demand under alternative scenarios.

\section{The model}

\section{A. Overview}

When banks can charge retail fees for cash withdrawal services, they have at least two broad profit motives for adopting ATMs. First, there is the pure stand-alone profit motive associated with the fee revenues from ATM cash withdrawals. Second, there is a strategic motive when the fees come in the form of foreign fees and/or surcharges, i.e. additional fees for consumers using ATMs from banks other than their own. These fees result in partial incompatibility between different ATM networks, providing banks with larger networks a strategic advantage over their rivals, as they can more easily attract new customers, or raise their rivals' costs. The recent ATM literature has largely focused on these two profit incentives for adopting ATMs, see e.g. McAndrews (2003) for an overview of the theoretical literature and Hannan et al. (2003), Ishii (2005), Gowrisankaran and Krainer (2007), Hannan and Borzekowski (2007), and Knittel and Stango (2008) for recent empirical contributions.

There is, however, also a third profit incentive for adopting ATMs, the pure cost-saving incentive, which is present even if banks cannot charge retail fees. A large ATM network induces customers to switch from branch to ATM cash withdrawals. This implies potentially important variable cost savings, but these need to be balanced against the fixed costs of setting up the ATM network. The cost-saving incentive is therefore larger if firms coordinate their ATM investment decisions and set up a shared ATM network.

The cost-saving incentive was already highlighted in the early literature as a main initial motive for ATM investment, but data limitations prevented a proper identification. Our analysis models and identifies precisely this cost-saving incentive in an environment where the two other profit incentives are absent because of zero retail fees, as in many European countries. Consistent with our industry background we first develop a model of coordinated 
ATM investment and demand in the absence of retail fees for cash withdrawals. This model will form the basis of our econometric analysis. We then consider the socially optimal outcome, and show how a social planner can intervene by regulating retail fees and/or providing subsidies per installed ATM. This will be used to perform a counterfactual policy analysis.

Our empirical model builds on earlier models of free entry, originating from Bresnahan and Reiss $(1990,1991)$ and Berry (1992). Berry and Waldfogel (1999) added a demand side to a free entry model, which enabled them to separately identify the demand and fixed cost parameters. Recent related work that incorporates both an entry and a demand equation can be found in e.g. Abraham et al. (2005), Ishii (2005), and Smith and O'Gorman (2008). Our own model also consists of an entry and demand equation, but the entry equation comes from a model of coordinated entry rather than one of free entry.

\section{B. Coordinated investment}

For a cross-section of local markets we observe the monthly number of ATM cash withdrawals per capita $Q_{A}$ and the number of shared ATMs $N$. For each market our model of coordinated ATM investment specifies how $Q_{A}$ and $N$ are simultaneously determined and depend on observed and unobserved market characteristics.

A market consists of $L$ consumers. Each consumer may withdraw cash at a branch of its bank or at a shared ATM, and the demands depend on the availability of ATMs $N$. Let ATM cash withdrawal demand, $Q_{A}=Q_{A}(N)$, be increasing in the number of ATMs $N$ : as $N$ increases, the average distance to an ATM decreases so that demand for cash withdrawals at ATMs increases. Similarly, let cash withdrawal demand at branches, $Q_{B}(N)$, be decreasing in $N$, reflecting the fact that consumers substitute out of branch cash withdrawals as ATM availability increases. Total cash withdrawal demand is $Q(N)=Q_{A}(N)+Q_{B}(N)$. Let $Q(N)$ be nondecreasing in $N$, i.e. an increase in the availability of ATMs leads to an increase in the total number of withdrawals, unless total cash withdrawal demand is inelastic with respect to $N$. In sum, increasing ATM availability leads to substitution from branch to ATM cash withdrawals, and to an overall expansion of cash withdrawals unless total cash demand is inelastic.

Banks coordinate their ATM investment decisions, in line with our industry background discussed in Section I. In each market, they choose $N$ to maximize their joint profits $\Pi(N)$, which consist of a stand-alone component $\Pi_{0}$, independent of $N$, and of several cost components that depend on $N$. There is a constant variable cost per cash withdrawal of $c_{A}$ at ATMs, and of $c_{B}>c_{A}$ at branches. The fixed cost of an ATM is $F$, which consists of both investment and maintenance costs. Since there are no retail fees for cash withdrawal 
at either ATMs or branches, the banks' joint profits in a given market are given by:

$$
\Pi(N)=\Pi_{0}-c_{A} Q_{A}(N) L-c_{B} Q_{B}(N) L-F N .
$$

This is simply the stand-alone profit component $\Pi_{0}$, minus the total variable costs from ATM and branch cash withdrawals, minus the fixed costs of all shared ATMs in the market. One may derive this aggregate model as the sum of the banks' individual profits. Two remarks are in order. First, the joint profits do not depend on the interchange fees, which banks pay to each other through the network operator. These interchange fees are simply transfers between banks and cancel out when adding up the banks' individual profits. If firms would choose ATMs in an uncoordinated way to maximize their individual profits, then the interchange fees become potentially relevant and may serve as a mechanism to soften competition for depositors; see Matutes and Padilla (1994) and Donze and Dubec (2006) for analyses of the strategic use of interchange fees when banks do not coordinate their ATM investment decisions.

Second, the stand-alone profit component $\Pi_{0}$ does not depend on $N$. This assumes that ATM availability does not increase aggregate demand for retail banking services. This is not unrealistic in our setting since most consumers already have at least one bank account, ${ }^{19}$ and since the shared ATMs are mainly used for cash withdrawals and not for other profitenhancing services. ${ }^{20}$

The banks' marginal joint profits from investing in $N$ ATMs are:

$$
\Pi(N)-\Pi(N-1)=-c_{A}\left(Q_{A}(N)-Q_{A}(N-1)\right) L-c_{B}\left(Q_{B}(N)-Q_{B}(N-1)\right) L-F .
$$

To interpret this economically, substitute out $Q_{B}(N)$ using $Q(N)=Q_{A}(N)+Q_{B}(N)$. The marginal joint profits can then be rewritten as:

$$
\Pi(N)-\Pi(N-1)=\underbrace{\left(c_{B}-c_{A}\right)\left(Q_{A}(N)-Q_{A}(N-1)\right) L}_{\begin{array}{c}
\text { variable cost saving } \\
\text { due to substitution }
\end{array}}-\underbrace{c_{B}(Q(N)-Q(N-1)) L}_{\begin{array}{c}
\text { variable cost increase } \\
\text { due to market expansion }
\end{array}}-F .
$$

This says that the change in banks' joint profits from one additional ATM consists of three components. First, an additional ATM induces consumers to substitute from high variable

\footnotetext{
${ }^{19}$ More than $98 \%$ of individuals already had a checking account by the end of the eighties, according to B.V.B. (1989).

${ }^{20}$ While aggregate demand for retail services can realistically be assumed to be independent of $N$, the banks' individual demands may potentially depend on $N$ (since banks with a dense branch network may benefit proportionately less from an increase in the number of shared ATMs). If banks have different margins, this may indirectly affect total profits in the market. However, since we do not observe the banks' profits at the market level, we rule out this possibility.
} 
cost cash withdrawals at branches to low variable cost cash withdrawals at ATMs. Second, an additional ATM may increase the total number of cash withdrawals, which generates additional variable costs. Third, there is a fixed cost involved in installing an additional ATM. If total cash withdrawal demand $Q(N)$ is inelastic, the second term cancels so that an increase in the number of ATMs reduces to a simple trade-off between variable cost savings and an additional fixed cost.

The banks choose the number of shared ATMs $N$ to maximize their joint profits. The optimal number of ATMs is $N=0$ if:

$$
\Pi(1)-\Pi(0)<0
$$

and $N=n>0$ if:

$$
\Pi(n+1)-\Pi(n)<0 \leq \Pi(n)-\Pi(n-1),
$$

i.e. the marginal joint profits from investing in $n$ ATMs should be positive, and the marginal joint profits from investing in $n+1$ ATMs should be negative. These are necessary conditions for joint profit maximization. They are also sufficient if the joint profits $\Pi(N)$ are concave in $N$, or equivalently if the marginal joint profits are decreasing in $N$. Note how the requirement of decreasing marginal joint profits in our model of coordinated entry parallels the common requirement of decreasing individual profits in traditional empirical models of free entry (as in e.g. Bresnahan and Reiss (1990)).

\section{Socially optimal investment}

The above model describes ATM investment when banks coordinate and cannot charge retail fees. This describes the "status quo situation" and forms the basis for our empirical analysis. In our policy counterfactuals presented in Section $\mathrm{V}$, we will compare the status quo with the social optimum, and assess how a regulator can set subsidies and/or retail fees to induce banks to implement the social optimum. Subsidies should be viewed as an instrument to directly promote ATM investment, but other means such as tax deductions may obviously also be possible. Retail fees mainly serve to influence ATM demand or usage, i.e. they may induce consumers to more often use ATMs given the available ATM network.

Suppose that the banks can charge a retail fee $t_{A}$ per ATM cash withdrawal and a retail fee $t_{B}$ per branch cash withdrawal. ${ }^{21}$ Consumer surplus $C S\left(N, t_{A}, t_{B}\right)$ is increasing in $N$ and decreasing in both fees $t_{A}$ and $t_{B}$. The per capita demand for cash withdrawals

\footnotetext{
${ }^{21}$ The ATM retail fee $t_{A}$ applies to all consumers regardless their bank affiliation. This rules out surcharges and foreign fees, so that ATMs remain fully compatible. The branch retail fee $t_{B}$ only applies to the banks' own customers since branches are incompatible.
} 
at ATMs is $Q_{A}\left(N, t_{A}, t_{B}\right)$. This is increasing in $N$ (as in the status quo situation where $\left.t_{A}=t_{B}=0\right)$, decreasing in $t_{A}$ and increasing in $t_{B}$. Similarly, per capita demand for cash withdrawals at branches is $Q_{B}\left(N, t_{A}, t_{B}\right)$, decreasing in $N$, increasing in $t_{A}$ and decreasing in $t_{B}$. The earlier status quo demands with zero fees are defined as $Q_{A}(N) \equiv Q_{A}(N, 0,0)$ and $Q_{B}(N) \equiv Q_{B}(N, 0,0)$. In Section III we develop an empirical utility-consistent specification that relates $C S\left(N, t_{A}, t_{B}\right)$ to $Q_{A}\left(N, t_{A}, t_{B}\right)$ and $Q_{B}\left(N, t_{A}, t_{B}\right)$.

Producer surplus is equal to the banks' joint profits. These now also include retail fee revenues and a subsidy $S$ per ATM:

$$
\Pi\left(N, t_{A}, t_{B}, S\right)=\Pi_{0}+\left(t_{A}-c_{A}\right) Q_{A}\left(N, t_{A}, t_{B}\right) L+\left(t_{B}-c_{B}\right) Q_{B}\left(N, t_{A}, t_{B}\right) L+(S-F) N,
$$

assumed to be concave in $N$. This extends the status quo profit function (1) to include the fees and subsidies, so $\Pi(N) \equiv \Pi(N, 0,0,0)$.

Total welfare in the presence of retail fees and subsidies, $W\left(N, t_{A}, t_{B}\right)$, is then the sum of producer surplus (5), consumer surplus and government revenues $-S N$, i.e.

$$
W\left(N, t_{A}, t_{B}\right)=\Pi\left(N, t_{A}, t_{B}, S\right)+C S\left(N, t_{A}, t_{B}\right)-S N .
$$

Note that total welfare does not directly depend on the subsidy $S$, since $S N$ is also part of $\Pi\left(N, t_{A}, t_{B}, S\right)$, and cancels out as it is just a transfer from the social planner to the banks. The social optimum or first-best solution then maximizes $W\left(N, t_{A}, t_{B}\right)$ with respect to $N$, $t_{A}$ and $t_{B}$.

The status quo situation may not be socially optimal for two reasons. First, banks choose the number of ATMs $N$ to maximize their own joint profits, and they do not take into account the effects on consumer surplus. Since consumer surplus $C S\left(N, t_{A}, t_{B}\right)$ is increasing in $N$ and $\Pi\left(N, t_{A}, t_{B}, S\right)$ is concave in $N$, the banks will underinvest in $N$ if the subsidy $S$ is equal to zero. ${ }^{22}$ Second, the retail cash withdrawal fees $t_{A}$ and $t_{B}$ are below variable costs and in fact regulated to zero. This implies that the demand for ATM withdrawals and especially for the high variable cost branch withdrawals may be distorted.

The social planner can induce the banks to implement the social optimum in a decentralized way, by first setting $S$ (instead of $N$ ), $t_{A}$ and $t_{B}$, and subsequently letting banks coordinate on $N$, given $S, t_{A}$ and $t_{B}$. Formally, use (5) to compute the banks' marginal joint profits with fees and subsidies, and obtain inequality conditions analogous to (4). These define the banks' joint profit maximizing number of ATMs $n^{*}\left(t_{A}, t_{B}, S\right)$, given the fees $t_{A}$ and $t_{B}$

\footnotetext{
${ }^{22}$ To see this, set $S=0$ and suppress the retail fees as arguments. When $N$ is continuous, the coordinated optimum $N^{C}$ solves $\Pi^{\prime}\left(N^{C}\right)=0$ and the social optimum $N^{S}$ solves $\Pi^{\prime}\left(N^{S}\right)+C S^{\prime}\left(N^{S}\right)=0$. The second term is positive by assumption, so that the first term is negative. Hence, $\Pi^{\prime}\left(N^{S}\right)<\Pi^{\prime}\left(N^{C}\right)$, so that $N^{S}>N^{C}$ by concavity of $\Pi(N)$. This argument still holds if $S$ is positive and sufficiently close to zero.
} 
and the subsidy $S$. The social planner then maximizes total welfare $W\left(n^{*}\left(t_{A}, t_{B}, S\right), t_{A}, t_{B}\right)$ with respect to the fees $t_{A}$ and $t_{B}$ and the subsidy $S$. Note that while the subsidy has no direct effect on welfare (as $S N$ is a transfer that cancels out), it has an indirect impact by influencing the banks' coordinated investment $n^{*}\left(t_{A}, t_{B}, S\right)$.

In our counterfactual policy analysis we will compare the status quo situation with the social optimum or first-best, as implemented through optimal fees $t_{A}$ and $t_{B}$ and a subsidy $S$. We will also consider two second-best solutions. In the "fees-only" case, the social planner keeps the subsidy at $S=0$, and chooses $t_{A}$ and $t_{B}$ to maximize $W\left(n^{*}\left(t_{A}, t_{B}, 0\right), t_{A}, t_{B}\right)$. In the "subsidies-only" case, the social planner keeps the fees at $t_{A}=t_{B}=0$, and chooses $S$ to maximize $W\left(n^{*}(0,0, S), 0,0\right)$. We will assess to which extent the fees-only and subsidies-only cases improve over the status quo situation and come close to the first-best.

\section{Econometric specification}

We now apply the model of coordinated investment and present the econometric specification. For a cross-section of markets we observe per capita ATM cash withdrawal demand $Q_{A}$ and the number of ATMs $N$. They are simultaneously determined and depend on observed and unobserved market characteristics. We develop a specification that will enable standard joint maximum likelihood estimation. In Section VI, we will provide several extensions.

\section{A. ATM demand or usage}

Section II allowed total demand for cash withdrawals $Q(N)$ to be increasing in $N$. We now assume that total demand is inelastic, $Q(N)=\bar{Q}$, so additional ATMs mainly involve substitution from branches to ATMs without raising the total number of cash withdrawals. This is not unreasonable, since our reduced form evidence, presented in Section I, suggested that consumers do not withdraw lower values per withdrawal as ATM availability increases. We can then write the ATM and branch demands as shares in total cash withdrawal demand, i.e. $Q_{A}(N)=s_{A}(N) \bar{Q}$ and $Q_{B}(N)=\left(1-s_{A}(N)\right) \bar{Q}$, where $s_{A}(N) \in[0,1]$ is the ATM cash withdrawal share. We specify this share, based on a model of consumers affiliated to the different banks.

Each consumer is affiliated to a bank $i$, and decides to make $\bar{Q}$ cash withdrawals at either one of the $N$ shared ATMs in the market, or at one of the $B^{i}$ branches of bank $i$ to which she is affiliated. She incurs a total price for an ATM cash withdrawal $p_{A}$, which is the sum of transport costs and retail fees. ${ }^{23}$ Hence, $p_{A}=p_{A}(N)=k d_{A}(N)+t_{A}$, where $k$ is the

\footnotetext{
${ }^{23}$ Gowrisankaran and Krainer (2007) also consider distance and price to enter additively. For an underlying
} 
travel cost per unit of distance, $d_{A}(N)$ is the expected distance to the nearest ATM and $t_{A}$ is the retail cash withdrawal fee (zero under the status quo). In general, $d_{A}(N)$ and $p_{A}(N)$ are decreasing in ATM density. More specifically, assume a spatial Poisson process for the consumers' and ATMs' locations, so that the expected distance to the nearest ATM follows a "square root law" in ATM density, i.e. $d_{A}(N)=\frac{1}{2} \sqrt{M / N}$, where $M$ is the market surface. ${ }^{24}$ The total price $p_{A}$ for an ATM cash withdrawal is therefore $p_{A}=p_{A}(N)=\frac{k}{2} \sqrt{M / N}+t_{A}$. Similarly, the total price for a branch cash withdrawal is $p_{B}^{i}=p_{B}\left(B^{i}\right)=\frac{k}{2} \sqrt{M / B^{i}}+t_{B}$.

A bank $i$ consumer has the following utilities from withdrawing cash at an ATM and a branch:

$$
\begin{aligned}
& u_{A}=v_{A}-\alpha p_{A}+\varepsilon_{A} \\
& u_{B}^{i}=v_{B}-\alpha p_{B}^{i}+\varepsilon_{B},
\end{aligned}
$$

where $v_{A}$ and $v_{B}$ are the intrinsic utilities from withdrawing cash at ATMs and branches, and $\varepsilon_{A}$ and $\varepsilon_{B}$ are logit error terms. ${ }^{25}$ Assuming random utility maximization, bank $i$ 's consumers have the following share of ATM cash withdrawals in their total withdrawals:

$$
s_{A}^{i}\left(p_{A}\right)=\frac{1}{1+\exp \left(v_{B}-v_{A}-\alpha\left(p_{B}^{i}-p_{A}\right)\right)},
$$

and they obtain the following expected surplus

$$
C S^{i}\left(p_{A}\right)=\frac{1}{\alpha} \ln \left(\exp \left(v_{A}-\alpha p_{A}\right)+\exp \left(v_{B}-\alpha p_{B}^{i}\right)\right) \bar{Q}
$$

The aggregate ATM cash withdrawal share, as a function of the number of ATMs $N$ in the market, is then

$$
s_{A}(N)=\sum_{i} w^{i} s_{A}^{i}\left(p_{A}(N)\right),
$$

where $w^{i}$ is the market share of bank $i$. We assume that the banks' market shares $w^{i}$ are independent of the number of ATMs, since the ATMs are shared and unlike incompatible ATMs do not provide a strategic advantage (Matutes and Padilla (1994) and Donze and Dubec (2008)). ${ }^{26}$

\footnotetext{
direct utility model, see McFadden and Train (1978).

${ }^{24}$ See for example Kolesar and Blum (1973) for a derivation. In Section VI we assess the plausibility of this functional form assumption.

${ }^{25}$ For example, $v_{A}$ and $v_{B}$ may reflect differences in service levels at branches and ATMs, e.g. more convenience at branches or lower queues at ATMs. Motivated by our discussion in Section I, we assume that $v_{A}$ and $v_{B}$ are no choice variables (at least not at the level of individual markets).

${ }^{26}$ We do not directly observe the market shares $w^{i}$ at the local market level. As a proxy we take the market share according to the number of branches and suitably rescale so that the national market shares according to our proxy equal the observed national market shares.
} 
The aggregate ATM cash withdrawal share $s_{A}(N)$ is the deterministic part of demand. Total per capita demand for cash withdrawals $\bar{Q}$ is the random part. It is a latent variable and is specified as:

$$
\ln \bar{Q}=X \beta+\eta_{1},
$$

where $X$ is a vector of observed market characteristics influencing $\bar{Q}$, and $\eta_{1}$ is an unobserved error term affecting total demand in the market.

Using $Q_{A}=s_{A}(N) \bar{Q}$ and (10), we obtain the following equation for ATM cash withdrawal demand:

$$
\ln Q_{A}=\ln s_{A}(N)+X \beta+\eta_{1}
$$

where $s_{A}(N)$ is given by (7) and (9). This is the ATM demand equation to be taken to the data.

Consider the various parameters in turn. First, the vector $\beta$ captures the effect of the market characteristics $X$ on ATM demand. Second, $\alpha$ captures the effect of the prices $p_{A}$ and $p_{B}^{i}$ on demand. Since $t_{A}=t_{B}=0$, the price effect is entirely identified from variation in the number of ATMs and branches across markets. Our model does therefore not separately identify the travel cost per unit of distance $k$ from $\alpha$. The price elasticity of demand does not depend on the value of $k .{ }^{27}$ But we need to know $k$ in our policy counterfactuals. Our approach will be to take a lower-end and an upper-end estimate based on outside information, and assess the sensitivity of the results.

Third, the parameter $v_{B}-v_{A}$ captures the intrinsic utility difference between a branch and an ATM cash withdrawal. While $v_{B}-v_{A}$ can be made a function of market characteristics, it is not well identified from $\beta$ since total cash withdrawal demand $\bar{Q}$ is unobserved. We therefore estimate $v_{B}-v_{A}$ as a constant, and assess identification by comparing total cash demand $\bar{Q}$ as predicted by our model with our information from an external source. ${ }^{28}$ Furthermore, in Section VI we will consider an alternative functional form for $s_{A}(N)$ to examine the robustness of our results.

\footnotetext{
${ }^{27}$ This follows from our specification for the total price $p_{A}(N)=\frac{k}{2} \sqrt{M / N}+t_{A}$. Using (7), (9) and (11), the price elasticity of demand is $E_{A}^{P}=\frac{d Q_{A}}{d P_{A}} \frac{P_{A}}{Q_{A}}=-\frac{\alpha p_{A}}{s_{A}} \sum_{i} w^{i} s_{A}^{i}\left(1-s_{A}^{i}\right)$. Since $t_{A}=0$, this does not depend on $\alpha$ and $k$ separately, but only on the product $\alpha k$. Furthermore, the elasticity of demand with respect to $N$ can be verified to be $E_{A}^{N}=\frac{d Q_{A}}{d N} \frac{N}{Q_{A}}=-\frac{1}{2} E_{A}^{P}$.

${ }^{28}$ We use (10) to compute predicted total cash demand as $\exp (X \beta)$, where $X$ is evaluated at sample means. We compare this with our nation-wide external number of $\bar{Q}=2.07$ withdrawals per month (discussed in Section I B).
} 


\section{B. ATM investment}

Banks coordinate their ATM investment decisions to maximize their joint profits. With inelastic demand for total cash withdrawals, i.e. $Q(N)=\bar{Q}$ and $Q_{A}(N)=s_{A}(N) \bar{Q}$, the marginal joint profits (2) from investing in an additional ATM simplify to:

$$
\Pi(N)-\Pi(N-1)=\left(c_{B}-c_{A}\right)\left(s_{A}(N)-s_{A}(N-1)\right) \bar{Q} L-F .
$$

Intuitively, investing in one more ATM involves a simple trade-off between an additional fixed cost $F$ against the variable cost savings from consumers substituting from branch to ATM cash withdrawals.

Substituting the marginal joint profits (12) in the necessary inequality conditions for optimality (3) and (4), the joint-profit maximizing number of ATMs is $N=0$ if

$$
\left(s_{A}(1)-s_{A}(0)\right) \bar{Q} L<\frac{F}{c_{B}-c_{A}}
$$

and $N=n>0$ if:

$$
\left(s_{A}(n+1)-s_{A}(n)\right) \bar{Q} L<\frac{F}{c_{B}-c_{A}} \leq\left(s_{A}(n)-s_{A}(n-1)\right) \bar{Q} L .
$$

These inequality conditions for joint profit maximization are also sufficient if $s_{A}(N)$ is concave in $N$. In the empirical analysis we will verify whether this is indeed the case at our obtained parameter estimates.

The investment model does not separately identify the fixed costs from the variable cost savings, but only the ratio. ${ }^{29}$ We specify this ratio as:

$$
\ln \frac{F}{c_{B}-c_{A}}=W \gamma+\eta_{2}
$$

where $W$ is a vector of observed market characteristics and $\eta_{2}$ is an unobserved error term. In Section VI we will extend this specification and allow $F$ to depend on $N$, thereby allowing for economies of density.

Substituting (15) in the inequality conditions (13) and (14), the number of ATMs is $N=0$ if

$$
\ln \left(s_{A}(1)-s_{A}(0)\right)+X \beta+\eta_{1}+\ln L \leq W \gamma+\eta_{2}
$$

and $N=n>0$ if

$\ln \left(s_{A}(n+1)-s_{A}(n)\right)+X \beta+\eta_{1}+\ln L<W \gamma+\eta_{2} \leq \ln \left(s_{A}(n)-s_{A}(n-1)\right)+X \beta+\eta_{1}+\ln L$.

\footnotetext{
${ }^{29}$ Ishii (2005) and Gowrisankaran and Krainer (2007) identify fixed costs by making assumptions on the variable costs of cash withdrawals. We do not make these assumptions at the estimation stage.
} 
These investment conditions are similar to the inequalities in an ordered probit model. They can be taken to the data, together with the demand equation (11). Note that the demand error term $\eta_{1}$ also enters the investment conditions (16)-(17). Intuitively, a high demand shock does not only imply a high ATM demand $Q_{A}$, but also high marginal joint profits, inducing banks to invest in many shared ATMs $N$. This emphasizes the importance of properly accounting for the fact that $Q_{A}$ and $N$ are simultaneously determined and may depend on the same unobserved factors. We turn to estimation next.

\section{Estimation}

For our cross-section of markets we observe the number of shared ATMs $N$ and ATM cash withdrawal demand $Q_{A}$ unless $N=0$. Defining

$$
\begin{aligned}
\varepsilon_{1} & \equiv \eta_{1} \\
\varepsilon_{2} & \equiv \eta_{2}-\eta_{1} \\
Z \theta & \equiv X \beta+\ln L-W \gamma \\
\tau_{n} & \equiv \ln \left(s_{A}(n)-s_{A}(n-1)\right),
\end{aligned}
$$

we can write the demand equation (11) and the investment inequalities (16)-(17) more compactly as follows:

$$
\begin{array}{ll}
\text { for } N=0: & Q_{A} \quad \text { unobserved } \\
& Z \theta+\tau_{1}<\varepsilon_{2}
\end{array} \quad \begin{aligned}
& \ln Q_{A}=\ln s_{A}(n)+X \beta+\varepsilon_{1} \\
& \text { for } N=n>0: \quad Z \theta+\tau_{n+1}<\varepsilon_{2} \leq Z \theta+\tau_{n} .
\end{aligned}
$$

The model thus essentially consists of a demand or usage equation, and investment inequalities as in an ordered probit model.

If one is not interested in the parameters determining ATM investment, one may in principle estimate the demand equation separately to learn about the causal impact of ATM availability on ATM cash withdrawal demand. However, OLS estimation would be unwarranted because of the endogeneity and selection problems stemming from the simultaneous determination of $Q_{A}$ and $N$. Intuitively, $Q_{A}$ and $N$ tend to be strongly correlated even in the absence of a causal relationship, because banks tend to invest in many ATMs under high demand shocks and in few ATMs under low demand shocks. For very low demand shocks, banks decide to invest in no ATMs, the traditional selection problem. Econometrically, the error terms $\varepsilon_{1}$ and $\varepsilon_{2}$ will be correlated since the demand error term $\eta_{1}$ enters both error 
terms through $\varepsilon_{1} \equiv \eta_{1}$ and $\varepsilon_{2} \equiv \eta_{2}-\eta_{1}$. This correlation arises here for economic reasons, i.e. the fact that the unobserved demand term $\eta_{1}$ influences the banks' investment decisions. ${ }^{30}$

One solution to deal with the simultaneity of $Q_{A}$ and $N$ is to include a correction term in the demand equation in the spirit of Heckman's (1978) and Amemiya's (1984) binary response selection models. Several recent papers extend these models to a non-binary response framework; see e.g. Mazzeo (2002), Watson (2007), Cohen and Mazzeo (2007) or Manuszak and Moul (2008). Our econometric specification enables a more efficient approach, i.e. estimate the demand and investment model jointly using maximum likelihood. Since we are interested in both the demand and cost side parameters, we follow this approach here. ${ }^{31}$

Identification of the effect of $N$ in the demand equation is achieved because of a natural exclusion restriction on the demand shifters $X$. We assume that population size $L$ does not directly affect per capita demand $Q_{A}$. At the same time it enters the investment equation (through $Z$ ) so it will be correlated with the endogenous variable $N .^{32}$

Let $f_{12}(\cdot), f_{1}(\cdot)$ and $f_{2}(\cdot)$ be the joint and marginal density functions of $\varepsilon_{1}$ and $\varepsilon_{2}$. We can then write the likelihood contributions for our sample of markets. For markets with $N=0$ we have

$$
P(N=0)=\int_{Z \theta+\tau_{1}}^{\infty} f_{2}\left(u_{2}\right) d u_{2},
$$

and for markets with $N=n>0$, we have

$$
f\left(\ln Q_{A} \mid N=n\right) P(N=n)=\int_{Z \theta+\tau_{n+1}}^{Z \theta+\tau_{n}} f_{12}\left(\varepsilon_{1}, u_{2}\right) d u_{2},
$$

where $\varepsilon_{1}=\ln Q_{A}-\ln s_{A}(n)-X \beta$ from (19).

Assume that $\varepsilon_{1}$ and $\varepsilon_{2}$ have a bivariate normal distribution, with means of zero, variances of $\sigma_{1}^{2}$ and $\sigma_{2}^{2}$ and a covariance of $\sigma_{12}$. Following standard practice in simpler Tobit II models

\footnotetext{
${ }^{30}$ The econometric model can be compared with Gronau's (1974) model of wage determination: wages are only observed for individuals who decide to participate in the labour market, and this participation decision may depend on the same unobserved factors ("skills") as the wages. The difference with our framework is that the participation decision in Gronau's model is a binary decision that matters for selection but does not directly influence wages. In contrast, the investment (or entry) decision is an ordered variable that matters for selection and in addition directly influences demand.

${ }^{31}$ To estimate the investment model, one could alternatively consider Pakes et al.'s (2006) moment inequality approach, which achieves partial identification in a more general setting (e.g. allowing for multi-agent strategic interactions and more general functional forms). One advantage of maximum likelihood in our application is that it enables simultaneous estimation of the demand and investment model, thereby accounting for common unobservables affecting both demand and investment.

${ }^{32}$ Berry and Waldfogel (1999) also used market size as an instrument in their demand equation. In principle, we could also consider cost shifters (in $W$ ) that do not directly affect demand (in $X$ ). In our application, we did not find natural candidates for variables that only affect cost and not demand, so we did not impose such restrictions (setting $X=W$ ).
} 
with normal errors, this enables us to write the second likelihood contribution as a product of (conditional) univariate normals. Denoting the standard normal distribution and density functions by $\Phi(\cdot)$ and $\phi(\cdot)$, respectively, we can thus rewrite the likelihood contributions as

$$
P(N=0)=1-\Phi\left(\frac{Z \theta+\tau_{1}}{\sigma_{2}}\right)
$$

and

$$
\begin{aligned}
f\left(\ln Q_{A}\right) P(N= & \left.n \mid \ln Q_{A}\right)= \\
& \frac{1}{\sigma_{1}} \phi\left(\frac{\varepsilon_{1}}{\sigma_{1}}\right)\left(\Phi\left(\frac{Z \theta+\tau_{n}-\left(\sigma_{12} / \sigma_{1}^{2}\right) \varepsilon_{1}}{\sqrt{\sigma_{2}^{2}-\sigma_{12}^{2} / \sigma_{1}^{2}}}\right)-\Phi\left(\frac{Z \theta+\tau_{n+1}-\left(\sigma_{12} / \sigma_{1}^{2}\right) \varepsilon_{1}}{\sqrt{\sigma_{2}^{2}-\sigma_{12}^{2} / \sigma_{1}^{2}}}\right)\right) .
\end{aligned}
$$

In many latent variable models the standard deviation $\sigma_{2}$ is not identified. In our application, $\sigma_{2}$ is identified since one parameter of the variables in $Z$ is restricted, i.e. the parameter for $\ln L$ entering $Z$ is equal to one; see (18).

\section{Empirical results}

The empirical model consists of the ATM demand or usage equation (11) and the investment or entry equation (16)-(17), as also summarized by (19). To estimate this model we observe $Q_{A}$ and $N$, and a set of market characteristics for a cross-section of 659 markets, as discussed in Section I and Tables 2 and 3. The market characteristics enter the demand equation (11) through $X$, and the entry equation (16)-(17) through $W$. Intuitively, $X$ and $W$ contain the market-level determinants of respectively total per capita cash withdrawals $\ln \bar{Q}$, and the ratio of fixed costs over variable cost savings $\ln F /\left(c_{B}-c_{A}\right)$. We will set $X=W$, hence we allow $\ln \bar{Q}$ and $\ln F /\left(c_{B}-c_{A}\right)$ to be affected by the same determinants. A first specification includes an intercept only, so that $\ln \bar{Q}$ and $\ln F /\left(c_{B}-c_{A}\right)$ are assumed to be uniform across markets. A second specification allows $\bar{Q}$ and $F /\left(c_{B}-c_{A}\right)$ to vary according to the following market demographics: the number of enterprises, the percentage of foreigners, young, elderly and unemployed, and a region dummy for Flanders.

Demand model only We first present the results from estimating the demand equation (11) only. This equation contains the ATM cash withdrawal share function $s_{A}(N)$, as given by (9), which is nonlinear in the parameters $v_{B}-v_{A}$ and $\alpha$. We therefore estimate the demand equation by maximum likelihood, but this does not take into account that $Q_{A}$ and $N$ are simultaneously determined. The results from the demand equation thus serve to highlight the endogeneity and selection issues associated with $N$. 
Table 6 shows the parameter estimates. The parameter $\alpha$ is estimated to be highly significant in both the specification without and with market characteristics influencing $\bar{Q}$. As discussed in Section III A, $\alpha$ measures how ATM usage is affected by the implicit price of an ATM withdrawal $p_{A}$. Since this implicit price is inversely proportional to $\sqrt{N}$, the significant estimate of $\alpha$ means that consumers withdraw significantly more cash at ATMs than at branches in markets where $N$ is high. The implied elasticity of demand $Q_{A}$ with respect to $N$ (evaluated at the sample mean) is quite high, 1.09 and 0.89 in the two respective specifications. This may however not describe the causal effect of $N$ on $Q_{A}$, but only a correlation since banks may have an incentive to invest in many ATMs when they observe a high ATM demand shock, and vice versa. The simultaneous model of ATM demand and investment will take this into account.

The second specification in Table 6 shows how market demographics affect the total number of per capita cash withdrawals $\bar{Q}$ (at ATMs and branches). Cash withdrawals tend to be significantly higher in markets with many elderly, which may indicate that this demographic group does not make use of electronic payments to the same extent. Cash withdrawal demand is significantly lower in the region of Flanders. The other demographics do not play a statistically significant role. The implied value of $\bar{Q}$ (at sample means) is precisely estimated at 1.28 in the first and 1.21 in the second specification. Note that this is significantly lower than the estimate of 2.07 cash withdrawals per capita and per month, available from our external source.

Simultaneous demand and investment model Table 7 displays the maximum likelihood estimates from the full simultaneous equations model (19), consisting of the demand or usage equation (11) and the investment equation (16)-(17). As discussed earlier, the model allows for correlation between the unobserved shocks affecting both demand and investment, using population as an exclusion restriction from the per capita demand equation. The model thereby accounts for endogeneity and selection issues associated with $N$. We first verified that demand is concave at the estimated parameters in all markets. Hence, the inequalities (16)-(17) are both necessary and sufficient for optimal investment.

First, consider the demand parameters $\left(\alpha, v_{B}-v_{A}\right.$ and $\left.\beta\right)$. Several parameters differ substantially from the estimates of the single equation model. Most notably, for both the specification without and with market characteristics, the estimate of $\alpha$ is almost three times smaller (and it is also more precise). This translates into lower elasticities of ATM demand $Q_{A}$ with respect to $N$, i.e. estimates of 0.65 in both specifications. Intuitively, the elasticity estimates of 1.09 and 0.89 in the single equation demand model only captured the correlation between $N$ and $Q_{A}$, which may be high if unobserved demand shocks induce banks to invest 
in many ATMs. The lower elasticity estimates of the simultaneous equation model capture the causal effect of $N$ on $Q_{A}$, which is what we are interested in when making welfare comparisons. As discussed in Section III A, our travel distance specification implies that the price elasticity of demand is twice as large as the elasticity with respect to $N$, i.e. -1.29 . Note that this is of the same order of magnitude as in Gowrisankaran and Krainer (2007) using a different approach. ${ }^{33}$

To further appreciate how the simultaneous equations model corrects for the endogeneity of $N$, consider the estimated correlation between the structural demand and cost errors $\eta_{1}$ and $\eta_{2}$, as computed from $\sigma_{1}, \sigma_{2}$ and $\sigma_{12} \cdot{ }^{34}$ These are relatively low in both specifications (respectively, -0.14 and -0.06 ) and insignificant in the second specification. However, they translate into highly significant negative correlations between our econometric errors $\varepsilon_{1}=\eta_{1}$ and $\varepsilon_{2}=\eta_{2}-\eta_{1}$, of respectively -0.73 and -0.69 . Intuitively, the demand error $\eta_{1}$ enters both the demand and the investment equation, so banks take into account that a high ATM demand shock $\eta_{1}$ also implies high marginal profits from investing in ATMs. Hence, both demand $Q_{A}$ and $N$ will tend to be high, which is properly accounted for through the covariance parameter $\sigma_{12}$. The single demand equation ignored this covariance, resulting in an overestimation of $\alpha$.

The parameter $v_{B}-v_{A}$ is positive and significant in both specifications: other things equal, consumers prefer a cash transaction at a branch over one at an ATM. This is as expected since consumers can combine a branch visit with several other services that are not necessarily available at shared ATMs. Finally, the second specification in Table 7 again shows that the total number of cash withdrawals $\bar{Q}$ is especially high among elderly and outside Flanders. The implied estimate of $\bar{Q}$ (at sample means) is now equal to 1.71 and 1.93 in the two respective specifications. While these numbers are still somewhat lower than the number of 2.07 from our external source, the underestimation is no longer statistically significant in contrast with the single equation demand estimates.

Second, consider the investment parameters $(\gamma)$, as shown in the second part of Table 7 . The first specification without demographics includes a highly significant intercept $\gamma_{0}=8.26$,

\footnotetext{
${ }^{33}$ Gowrisankaran and Krainer (2007) also have an additive specification for price and distance, as we do. In contrast with us, they observe different price policies in two U.S. states; but they do not observe the actual ATM cash withdrawals. On p. 32, they report that a price increase by 10 cents lowers the probability of using a particular ATM from $50 \%$ to $45 \%$. Evaluated at a mean (median) price of $\$ 1.5(\$ 0.5)$, this implies a price elasticity of $-1.5(-0.5)$.

${ }^{34}$ Given the mean-zero bivariate normal distribution of $\varepsilon_{1}$ and $\varepsilon_{2}$, the structural errors $\eta_{1}=\varepsilon_{1}$ and $\eta_{2}=\varepsilon_{1}+\varepsilon_{2}$ have a mean-zero bivariate normal distribution with variances of $\sigma_{1}^{2}$ and $\sigma_{1}^{2}+\sigma_{2}^{2}+2 \sigma_{12}$, and a covariance of $\sigma_{1}^{2}+\sigma_{12}$. The correlation between $\eta_{1}$ and $\eta_{2}$ then equals $\frac{\sigma_{1}^{2}+\sigma_{12}}{\sigma_{1} \sqrt{\sigma_{1}^{2}+\sigma_{2}^{2}+2 \sigma_{12}}}$.
} 
which translates in a precise estimate of the ratio of the fixed cost over variable cost savings, i.e. $F /\left(c_{B}-c_{A}\right)=\exp \left(\gamma_{0}\right)=3,876$, with a $95 \%$ confidence interval of $[3,556 ; 4,197]$. The second specification with demographics implies a very similar ratio of 3, 932 (at sample means). To assess whether this ratio is reasonable, we can use fixed and variable cost information from our external source, discussed earlier in Section I A. According to the network operator Banksys the monthly fixed costs of an ATM are $€ 2,300$. Our estimated ratio $F /\left(c_{B}-c_{A}\right)$ then implies that the variable cost savings from cash withdrawals at ATMs instead of branches amount to $€ 0.59$ and $€ 0.58$ in the two respective specifications. This is similar to the U.S. and European estimates obtained from direct cost information (as reviewed in Section I A).

To evaluate the fit of the full simultaneous equations model, we compare the model's predicted number of ATMs with the observed number in each market. To predict $N$, we take a large number of draws of $\eta_{1}$ and $\eta_{2}$ for each market (100 draws). For each market and each draw, we compute the joint profit maximizing $N$ based on the parameter estimates and equilibrium condition (17). For each market, we then compute the average of $N$ over all draws, and take this as the predicted $N$ for the given market. Similar to Berry and Waldfogel (1999), we then compute the correlation between the predicted and the observed number of ATMs for the markets. This is equal to 0.78 and 0.81 in the models without and with demographics, implying an $R^{2}$ of, respectively 0.60 and 0.65 .

Sensitivity analysis Our discussion focused on two specifications, based on the sample of 659 non-urban markets. We also estimated the model using the complete sample of 842 markets, i.e. including the urban areas. Tables A1 and A2 in Appendix A show that most of the parameter estimates are similar, and they do not generate qualitatively different conclusions. We have also considered a sensitivity analysis regarding various specification assumptions. We discuss these in detail in Section VI.

\section{Policy counterfactuals}

We use our parameter estimates to compare the status quo situation of coordinated entry and zero retail fees with several alternative scenarios with positive retail fees and/or subsidies per ATM. We ask how these alternative scenarios influence ATM investment (a highly sensitive political issue because of a perceived lack of geographic coverage), ATM demand or usage, and total welfare. 


\section{A. Approach}

We compute the predicted number of ATMs, the number markets without an ATM and the various welfare components (consumer surplus, producer surplus and government revenues) under various scenarios. The first one is simply the status quo scenario, in which banks coordinate ATM investment, charge zero retail cash withdrawal fees at branches and ATMs and obtain no subsidies per ATM. The second scenario is the social optimum or first-best solution. As discussed in Section II, the first-best can be obtained in two ways: in a centralized way by maximizing total welfare (6) with respect to the number of ATMs $N$ and cash withdrawal fees $t_{A}$ and $t_{B}$; or in a decentralized way through welfare-maximizing retail fees and subsidies while allowing banks to coordinate on $N$ given these fees and subsidies. The third and fourth scenarios are the second-best "fees-only" and "subsidies-only" scenarios, where the social planner optimally chooses either fees or subsidies but not both, and banks subsequently coordinate on $N$.

The status quo predictions follow the approach used for computing the model's fit as described in the previous section. The predictions of the other three scenarios are similar but slightly more involved. To illustrate, we explain the approach of the third scenario, where the social planner optimally sets the retail cash withdrawal fees, but maintains zero subsidies. For each market we take a large number of draws of $\eta_{1}$ and $\eta_{2}$ (i.e. 100 draws). ${ }^{35}$ For each market and each draw we take a possible fee structure $\left(t_{A}, t_{B}\right)$, we compute the joint profit maximizing number of ATMs $n^{*}\left(t_{A}, t_{B}, 0\right)$, based on the equilibrium condition (17), and compute total welfare $W\left(n^{*}\left(t_{A}, t_{B}, 0\right), t_{A}, t_{B}, 0\right)$. We then search over alternative $\left(t_{A}, t_{B}\right)$ to find the fees that maximize total welfare. We repeat this approach for each market and each draw to obtain optimal fees and the implied welfare components for each market and each draw. We subsequently compute summary information across markets on the optimal retail fees and/or subsidies, on ATM investment and usage, and welfare. We present both the means and the standard errors from our 100 draws.

This approach assumes that the social planner can set optimal fees specific to each market. In reality, it would be more reasonable to assume that a regulator sets a uniform fee for all markets. We also followed that approach and obtained very similar results. However, we prefer to present the results from the optimal market-specific fees since this provides a sharper economic intuition and a clear-cut benchmark for first-best.

Since our empirical model assumes that total cash withdrawal demand $\bar{Q}$ is inelastic, optimal welfare only depends on the difference $t_{B}-t_{A}$ and not on the levels of $t_{A}$ and

\footnotetext{
${ }^{35}$ We take these draws from the normal distribution. This differs from Berry and Waldfogel (1999), who take draws from a truncated normal distribution such that the status quo is perfectly predicted. We also followed their approach and obtained similar results.
} 
$t_{B}$ separately. This facilitates the exposition and especially the calculations as it is only necessary to search over the difference $t_{B}-t_{A} \cdot{ }^{36}$

To perform our counterfactuals we need some identification assumptions. The empirical model only identified the ratio $F /\left(c_{B}-c_{A}\right)$. Based on our external estimate, we assume that $F=€ 2,300$, implying that $c_{B}-c_{A}=€ 0.59$. The results were similar for higher values of fixed costs with correspondingly higher variable cost savings. The empirical model does also not identify the travel cost per unit of distance $k$ (in $€ / \mathrm{km}$ ) from the price parameter $\alpha$. In our welfare analysis, a high assumed value of $k$ implies a high weight to consumer surplus relative to producer surplus. We therefore use two alternative values $k=€ 0.10$ and $k=€ 0.25$. The higher value is a commonly used by companies and tax authorities to reimburse travel costs. The lower value roughly corresponds to Gowrisankaran and Krainer's (2007) estimate of ATM travel costs (using a different model and data). We focus our discussion on the results for $k=€ 0.25$, and present the results for $k=€ 0.10$ as a robustness check in Table A3 of Appendix A.

\section{B. Results}

Status quo The first column of Table 8 shows the 1994 status quo predictions, when fees and subsidies are zero. The predicted total number of ATMs across all markets is 490 (standard error of 19), which is close to the actually observed number of ATMs of 486. The predicted number of markets without an ATM is 330, again not significantly different from the actual number of unserved markets of 349. Hence, under the status quo over one half of the non-urban markets are unserved by shared ATMs.

The low density of the ATM network is reflected in a low number of per capita ATM cash withdrawals under the status quo. The model predicts monthly per capita ATM cash withdrawals of 0.59 , which is close to and not significantly different from the observed number of 0.56. This is only one third of total cash withdrawals at ATMs and branches, hence ATM usage is rather low.

First-best The second column of Table 8 shows the first-best predictions. As discussed, these can be obtained either in a centralized way by choosing $N$ and $t_{B}-t_{A}$, or in a

\footnotetext{
${ }^{36}$ Concretely, in our third scenario with optimal fees and no subsidies we search over 201 possible values $t_{B}-t_{A}$ in the interval $(-5,5)$ for each market and each draw. Since there are 659 markets and 100 draws per market, the equilibrium number of $\operatorname{ATMs} n^{*}\left(t_{A}, t_{B}, 0\right)$ has to be computed over 13 million times. In the first-best scenario, for each market and each draw we in addition consider 53 possible subsidy values $S$ in the interval $(0,2600)$ for each price difference $t_{B}-t_{A}$. This amounts to about 702 million computations of the socially optimal number of $\operatorname{ATMs} n^{*}\left(t_{A}, t_{B}, S\right)$.
} 
decentralized way by setting $S$ and $t_{B}-t_{A}$, and subsequently allowing banks to continue to coordinate on $N$. Table 8 shows that a regulator would like to invest in a much larger shared ATM network: the total number of ATMs across markets under the social optimum is 1018 (standard error of 20), which is more than twice as much as the status quo number of 490 . The number of unserved markets is almost three times lower, dropping from 330 under the status quo to 114 under the social optimum. Finally, ATM usage is substantially larger in the social optimum: the number of cash withdrawals at ATMs increases from a monthly per capita average of 0.59 to 1.42 , amounting to more than two thirds of total cash transactions (at ATMs and branches).

One may therefore conclude that ATM investment and usage have been considerably lower than socially optimal. The retail fees and subsidies that implement the social optimum are essentially cost-based. Table 8 shows that the optimal fee premium for branch withdrawals $t_{B}-t_{A}$ is on average $€ 0.62$, close to the extra variable costs at branches of $c_{B}-c_{A}=€ 0.59$. The accompanying optimal ATM subsidy $S$ is $€ 2,236$, close to the fixed costs of an ATM of $€ 2,300){ }^{37}$

Total welfare for our sample of non-urban areas in Belgium increases by $€ 2.16$ million per month. Banks capture the largest share of the welfare gains: they would receive an additional $€ 6.4$ million per month, because of the subsidies, the fee revenues from cash withdrawals at branches and the variable cost savings from consumers substituting to ATMs. The government loses $€ 2.27$ million per month, due to the subsidies paid to the banks. Perhaps surprisingly, consumers lose $€ 1.97$ million per month despite the much more dense shared ATM network. Their benefits in the form of reduced travel costs to ATMs are overwhelmed by the losses from the fees they have to pay for branch withdrawals.

Second-best How close can one reach to the first-best through either "subsidies-only" or "fees-only"? Consider first the subsidies-only case, shown in the third column of Table 8. This should be interpreted as a policy to directly promote ATM investment, since banks do not take into account the positive effects of their investments on consumer surplus. (Other policies such as tax deductions may achieve the same outcome.) The optimal subsidy per ATM is on average $€ 1,545$, which is about two thirds of the fixed cost of an ATM. This results in a substantial increase in the number of ATMs, from 490 to 1022, very close to the socially optimal number. Similarly, there is a considerable drop in the number of markets

\footnotetext{
${ }^{37}$ When $N$ is a continuous variable, it can easily be shown that the social optimum requires $t_{B}-t_{A}=c_{B}-c_{A}$ and $S=F$. This is not necessarily true when $N$ can only take integer values as in our set-up, but the simulation results are nevertheless close. This tendency to cost-based optimal fees and subsidies also explains why the standard errors of the predicted fees and subsidies are so low.
} 
without an ATM, from 330 to 148 markets, which is again close to geographic coverage in the social optimum. However, the monthly number of cash withdrawals at ATMs increases only moderately from 0.59 to 0.84 , which is still far below the social optimum of 1.42 . As a result of the increased investment, consumers gain $€ 1.03$ million per month: they save on travel costs because of the more dense ATM network. ${ }^{38}$ Banks also gain, at the expense of the government. The total welfare gains amount to only $€ 0.59$ million per month, far less than the maximum attainable welfare gains of $€ 2.16$ million per month under the first-best. Intuitively, this is because the pure promotion of ATM investment is a rather expensive way to promote usage of the cost-saving technology.

Now consider the fees-only case, shown in the final column of Table 8. The optimal extra retail fee for cash withdrawals at branches is on average $€ 0.47$ per transaction, slightly below the extra variable cost of about $€ 0.60$ for cash withdrawals at branches. The extra retail fee has a small negative effect on the banks' investment decisions, hence geographic coverage remains suboptimal. Intuitively, this is because the retail fee premium on branch transactions make it relatively more profitable to serve customers at branches, thus reducing the variable cost saving incentive from investing in more ATMs. ${ }^{39}$ However, the fees induce consumers to substitute out of branches and use ATMs more often: the number of cash withdrawals at ATMs increases from 0.59 to 0.88 per capita and per month. These changes result in a monthly increase of total welfare by $€ 1.12$ million, largely because of profit increases at the expense of consumers. Interestingly, a policy of raising retail fees without subsidies is thus more effective in improving welfare than a policy of introducing subsidies while keeping fees at zero, despite the fact that the latter policy brings ATM investment closely in line with the first-best. This is because a fees-only policy also induces consumers to substitute to ATM withdrawals, hence realizing variable cost savings without the need of extra fixed cost investments in ATMs.

Note that a fees-only policy is even more effective than a subsidies-only policy if we assume a lower cost per $\mathrm{km}, k=€ 0.10$, as shown in Table A3 of Appendix A. Intuitively, under a lower $k$ consumers receive less weight in total welfare, so that fees become an even more effective instrument to improve welfare.

Summary The policy counterfactuals show that there is substantial underinvestment in the shared ATM network. This follows from the absence of strategic investment incentives,

\footnotetext{
${ }^{38}$ The increase in consumer surplus contrasts with the consumer losses in the first-best, where also fees were introduced.

${ }^{39}$ It is interesting to contrast this with the introduction of surcharges in the U.S. These fees refer to ATM fees leading to partial network incompatibility. This induced banks to invest considerably more in ATMs.
} 
and provides an interesting real world counterfactual to the U.S., where ATM networks are partially incompatible. Furthermore, ATM usage is too low; consumers use branches too often to withdraw cash. A policy that combines cost-based cash withdrawal fees and ATM subsidies can achieve the social optimum and raise welfare to a significant extent. A second-best fees-only policy is more effective in raising welfare than the direct promotion of investment through a subsidies-only policy, since it induces consumers to substitute to ATM withdrawals without requiring expensive extra investments in ATMs.

\section{Extensions}

To assess the robustness of our results, we extend our model in several ways. First, we develop an alternative travel cost model. Second, we consider an alternative functional form for our logit ATM market share specification (7). Third, we introduce the possibility of economies of density by allowing the fixed costs per ATM to depend on the number of ATMs in the market.

\section{A. Alternative travel cost model}

In our travel cost model consumers either withdraw cash at the nearest ATM, or at the nearest branch of their own bank $i$. To compute the distances to the nearest ATM and branch, we assumed that consumers and ATM/branch locations follow a spatial Poisson process. Under this assumption the expected travel distance to the nearest ATM follows a square root law, $d(N)=\frac{1}{2} \sqrt{M / N}$, i.e. the expected distance is inversely proportional to the ATM density in the market $N / M$ (number of ATMs per $\mathrm{km}^{2}$ ). Similarly, the expected distance to the nearest branch of bank $i$ is $d\left(B^{i}\right)=\frac{1}{2} \sqrt{M / B^{i}}$.

In practice, the distribution of consumers and ATMs may show some clustering. If this is the case, our square root measure based on the Poisson process would overestimate the expected distance to the nearest ATM; it would also overestimate the marginal effect of an increase in ATM density on the expected distance. To assess the validity of our travel cost model, we therefore looked into more detail at the spatial distribution of consumers, ATMs and branches. We divided our sample of 659 markets into 12,754 highly disaggregate consumer locations $\ell$, so on average we obtain 19.4 locations per market. ${ }^{40}$ We geocoded the ATM and branch locations to compute the consumers' average travel distances within each market. Formally, the population-weighted average travel distance to the nearest ATM in a

\footnotetext{
${ }^{40}$ These locations are the "statistical sectors" defined by the Belgian National Institute of Statistics, and we obtained population information at this level of detail, with an average of 450 inhabitants per sector.
} 
market is $\bar{d}_{A}=\sum_{\ell} d_{A}^{\ell} \omega^{\ell}$, where $d_{A}^{\ell}$ is the distance of a consumer at the centroid of location $\ell$ to the nearest ATM, and $\omega^{\ell}$ is the population weight at location $\ell$. Similarly, the average travel distance to the nearest branch of bank $i$ is $\bar{d}_{B}^{i}=\sum_{\ell} d_{B}^{i \ell} \omega^{\ell}$.

The left panel of Table 9 summarizes the actual average travel distances $\bar{d}_{A}$ and $\bar{d}_{B}^{i}$ for our sample of markets, and compares this with the expected travel distances based on our square root measures $d(N)$ and $d\left(B^{i}\right)$. This shows that $\bar{d}_{A}$ and $d(N)$ are in fact strongly correlated across markets (correlation coefficient of 0.75 ). Similarly, $\bar{d}_{B}^{i}$ and $d\left(B^{i}\right)$ are strongly correlated for all of the eight banks $i$. Furthermore, the actual travel distances are of a similar magnitude as the square root measures, though generally lower. For example, the average of $\bar{d}_{A}$ across markets is $2.00 \mathrm{~km}$, whereas the average of $d(N)$ is $2.71 \mathrm{~km}$.

To further assess the validity of our square root measure, we specified $\bar{d}_{A}=\varphi_{0} M^{\varphi_{1}} N^{\varphi_{2}}$ for the ATM distances, and similarly for the branch distances $\bar{d}_{B}^{i}$. For our cross-section of markets we then regressed $\ln \bar{d}_{A}$ on $\ln M$ and $\ln N$. Analogously, we regressed $\ln \bar{d}_{B}^{i}$ on $\ln M$ and $\ln B^{i}$. If our square root measure is correct we should obtain estimates of $\varphi_{0}=\frac{1}{2}$, $\varphi_{1}=\frac{1}{2}$ and $\varphi_{2}=-\frac{1}{2}$. The right panel of Table 9 shows that $\varphi_{1}$ and $\varphi_{2}$ are typically quite close to $\frac{1}{2}$ and $-\frac{1}{2}$, and they differ significantly from these values in only 4 out of 18 cases. Interestingly, one of these is the $\varphi_{2}$-parameter in the ATM distance regression $(-0.34)$; while this is close to $-\frac{1}{2}$, this indicates that there is indeed some clustering in ATMs. Finally, the scale parameter $\varphi_{0}$ tends to be significantly below the theoretical value of $\frac{1}{2}$, but it is still of a comparable order of magnitude (around 0.3-0.4).

In sum, these results suggest that our square root measure for the expected travel distances is a reasonable first approximation. It is a quite good proxy for the marginal effect of increasing branch density on the expected distance. But it tends to slightly overestimate the marginal effect of increasing ATM density on the expected distance, as well as the level of the actual average distances. This can be interpreted as evidence of some clustering in the distribution of consumers and locations.

To assess the robustness of our results we therefore re-estimated the demand and investment model based on the more general functional form for the expected travel distances to the nearest ATM and branches. So for the ATM distances, we specify $d(N)=\varphi_{0} M^{\varphi_{1}} N^{\varphi_{2}}$, where $\varphi_{0}, \varphi_{1}, \varphi_{2}$ are the regression coefficients in Table 9 ; and we proceed similarly for the branch distances. The empirical results for the full demand and investment model with this more general functional form for distance are shown in the first column of Table 10. This can be compared with our earlier results for the benchmark case with our square root distance proxy, i.e. the second column of Table 7. A comparison shows that the results are very similar to our original specification. The only notable change is the estimate of $\alpha$, but the implied elasticities remain similar. Our policy counterfactuals (not shown) also remain very 
similar to our benchmark specification. ${ }^{41}$

\section{B. Alternative ATM share specification}

Our logit ATM share specification (7) contained the parameter $v_{B}-v_{A}$, the intrinsic utility from withdrawing cash at branches instead of ATMs. As explained in Section III A, $v_{B}-v_{A}$ is not well identified from $\beta$, the parameter vector entering total cash withdrawal demand $\bar{Q}$. The reason is that we only observed ATM demand $Q_{A}$ and not total cash withdrawal demand $\bar{Q}$. Our approach to this identification problem was to identify the $v_{B}-v_{A}$ from $\beta$ through the non-linearity of the market share specification (7), and subsequently assess whether $\bar{Q}$ as predicted from (10) was close to our country-level estimate of $\bar{Q}$ from an external source. The estimates of our simultaneous demand and investment model showed that this was indeed the case.

To shed further light on the identification issue, we now consider an alternative ATM share specification. Suppose consumer surplus of a depositor affiliated to bank $i$ takes the following form:

$$
C S^{i}\left(p_{A}\right)=\frac{1}{\alpha}\left(v_{B}-\alpha p_{B}^{i}+\exp \left(v_{A}-\alpha p_{A}-\left(v_{B}-\alpha p_{B}^{i}\right)\right)\right) \bar{Q} .
$$

Applying Roy's identity, a bank $i$ consumer's share of ATM cash withdrawals in total cash withdrawals is

$$
s_{A}^{i}\left(p_{A}\right)=\exp \left(-\left(v_{B}-v_{A}\right)+\alpha\left(p_{B}^{i}-p_{A}\right)\right) .
$$

We refer to (21) as our semilog specification, as opposed to our earlier logit specification (7). ${ }^{42}$ Substituting (21) in (9) and (11), we obtain the following specification for ATM transaction demand

$$
\ln Q_{A}=-\left(v_{B}-v_{A}\right)+\ln \sum_{i} w^{i} \exp \left(\alpha\left(p_{B}^{i}-p_{A}\right)\right)+X \beta+\eta_{1} .
$$

\footnotetext{
${ }^{41}$ This spatial extension is still based on a representative consumer choosing between ATM and branch withdrawals, but using a more realistic expected distance specification. We also followed a second approach, where we account more explicitly for the heterogeneity of consumer, ATM and branch locations within a market. The demand side is in the spirit of Davis (2006) and Ishii (2005). The entry side is, however, challenging: it requires establishing the optimality of the observed ATM location vector in each market relative to all possible alternative locations (which may be at the branches of all banks in the market). We considered a simplified approach that preserves the ordered structure of the entry model, where we only consider optimality with respect to one added and one dropped ATM at randomly assigned locations. This approach again gave similar results. Details are available from the authors on request.

${ }^{42}$ Our logit share specification was derived from a discrete choice model, but it could equivalently also be derived from a representative consumer model with indirect utility (8). See Anderson, de Palma and Thisse (1992).
} 
This shows that $v_{B}-v_{A}$ now enters linearly, so that it is clearly not identified from the intercept $\beta_{0}$ in $\beta$, not even through the functional form. After estimating the model, we therefore set $v_{B}-v_{A}$ and $\beta_{0}$ such that the predicted $\bar{Q}$ is equal to 2.07 for the representative market.

The empirical results for the semilog specification (simultaneous demand and investment model) are shown in the second column of Table 10. A comparison shows that the results are very similar to the benchmark specification; note in particular the similar predictions for $s_{A}, E_{A}^{N}$ and $F /\left(c_{B}-c_{A}\right)$; the same is true for the policy counterfactuals (not shown).

\section{Economies of density}

Our investment specification assumed a fixed cost $F$ per ATM, independent of the number of ATMs in the market. In practice, it is possible that there are economies of density in setting up an ATM network. For example, the network operator's fixed maintenance costs may be lower when there are many nearby ATMs in the same market. Holmes (2008) provides a thorough analysis of economies of density based Walmart's location decisions. To account for economies of density we extend our specification of the ratio of fixed cost over variable cost savings (15) to

$$
\ln \frac{F}{c_{B}-c_{A}}=W \gamma+\lambda \ln N+\eta_{2} .
$$

If $\lambda<0$, there are economies of density since an increase in $N$ lowers the fixed cost $F$ per ATM (assuming that $c_{B}-c_{A}$ is independent of $N$ ).

The empirical results are shown in the third column of Table 10. We indeed find evidence of economies of density, since $\lambda=-0.36$ (standard error of 0.10). ${ }^{43}$ Most other parameter estimates are close to those in the first column, where $\lambda=0$. Since the ratio of fixed cost over variable cost savings is no longer constant, we present the ratio for markets with $N=1$ and $N=2$ (covering $90 \%$ of the markets with an ATM). The ratio is equal to 4,176 when $N=1$, and 3,264 when $N=2$, compared with our earlier constant estimate of 3,932 . We also considered policy counterfactuals, continuing to assume a constant subsidy $S$ per ATM. Because of the economies of density, the optimal subsidy per ATM was on average lower than in our baseline case without economies of density, but most other results remained similar.

\footnotetext{
${ }^{43}$ This was further confirmed in a specification where $\ln \frac{F}{c_{B}-c_{A}}$ depends non-parametrically on $N$, by specifying fixed effects $\lambda_{n}, n=2, \ldots, 6$. This specification showed that most economies of density were realized from adding the second ATM.
} 


\section{Conclusion}

We have analyzed investment and usage of a shared ATM network. Because ATMs are compatible and there are no retail fees, banks have no strategic or revenue motives but only a pure cost-saving incentive for investing in ATMs. Furthermore, because there are no retail fees, consumers may have insufficient incentives to use the available cost-saving ATMs. We developed an empirical model of coordinated investment and ATM cash withdrawal demand, and applied it to the Belgian market in the early nineties. Our results showed that banks substantially underinvested in the shared ATM network, in contrast with the findings for the U.S., showing overinvestment in ATM networks with partial incompatibility. Furthermore, we found that usage of the ATM network is too low because of the zero retail fees for cash withdrawals at branches. A direct promotion of investment (through subsidies or other means) can improve efficiency, but the introduction of proper retail fees on cash withdrawals at branches would be more effective in raising welfare, even if it does not encourage investment per se.

Our results stress that policy makers should focus on providing both the correct investment incentives to banks and the correct price incentives to consumers. This conclusion extends to many other European countries, where a similar institutional environment existed (i.e. single shared networks, with common ownership and no retail fees for cash withdrawals). Furthermore, our findings provide and interesting contrast with the recent U.S. experience, where the introduction of surcharges in the mid-nineties led to a substantial increase in ATM investment. Combining these results, one may conclude that full compatibility without retail fees implies too little investment, whereas partial compatibility because of surcharges may lead to overinvestment.

The joint importance of investment and usage extends to many other technologies than ATMs. We consider two closely related examples, where investment also refers to acquiring geographic coverage. First, the success of internet broadband depends on both the operators' investments in geographic coverage and on the users' decision to adopt, as has been stressed by policy makers such as the OECD (2008). Goolsbee (2006) studied the effects of a broadband tax in the U.S., which does not only directly reduce user demand, but also indirectly reduces the operators' incentives to invest since it becomes more difficult to cover fixed costs. Second, the success of environmentally friendlier fuels for cars does not only depend on the consumers' willingness to adopt cars with new engines, but also on the companies' willingness to make the new fuels broadly available at gasoline stations. As discussed in Stoneman (2002, Ch. 15), availability was no issue in Europe for the introduction of the unleaded gasoline engine, because of a European Commission mandate (85/210/EC) requir- 
ing that unleaded gasoline be available nation-wide from October 1989 onwards. For other types of gasoline there are often no such mandates, and nation-wide availability may be an issue, as for LPG. In future research it would be interesting to apply our empirical approach to these or other applications. 


\section{References}

Abraham, Jean Marie, Martin Gaynor, and William B. Vogt. 2005. "Entry and Competition in Local Hospital Markets." NBER Working paper 11649.

Amemiya, Takeshi. 1984. "Tobit models: A Survey." Journal of Econometrics, 24: 3-61.

Anderson, Simon P., Andre De Palma, and Jacques-Francois Thisse. 1992. Discrete choice theory of product differentiation. Cambridge: MIT press.

Arrow, Kenneth J. 1962. "Economic Welfare and the Allocation of Resources for Inventions." in The Rate and Direction of Inventive Activity, ed. R. Nelson, Princeton: Princeton University Press.

Banco de Portugal. 2007. "Retail Payment Instruments in Portugal: Costs and Benefits." Study July 2007.

Bank for International Settlements. 1999, 2003. "Payment and settlement systems in selected countries." Committee on Payment and Settlement Systems Red Book.

Belgische Vereniging van Banken. 1987, 1994a, 1997, 2004. "Statistisch Vademecum van de Banksector." Aspecten en Documenten.

Belgische Vereniging van Banken. 1989. "Het menselijk kapitaal in de banksector." Aspecten en Documenten.

Belgische Vereniging van Banken. 1994b. "De banken in 1994: individuele gegevens" Aspecten en Documenten.

Belgische Vereniging van Banken. 1995. Bankvestigingen in België. Brussel: Belgische Vereniging van Banken.

Berger, Allen N. 1985. "The Economics of Electronic Fund Transfers." Working paper Board of Governors of the Federal Reserve System.

Bernhardt, Dan, and Nadia Massoud. 2005. "Endogenous ATM Networks and Pricing." mimeo, $30 \mathrm{p}$.

Berry, Steven T. 1992. "Estimation of a Model of Entry in the Airline Industry." Econometrica, 60(4): 889-917. 
Berry, Steven T., and Joel Waldfogel. 1999. "Free entry and social inefficiency in radio broadcasting." RAND Journal of Economics, 30(3): 397-420.

Bresnahan, Timothy F., and Peter C. Reiss. 1990. "Entry in monopoly markets." Review of Economic Studies, 57(4): 531-553.

Bresnahan, Timothy F., and Peter C. Reiss. 1991. "Entry and Competition in Concentrated Markets." Journal of Political Economy, 99(5): 977-1009.

Carlton, Dennis W., and Alan S. Frankel. 1995. "Antitrust and Payment Technologies." Federal Reserve Bank of St. Louis Review, November/December 1995: 41-54.

Chioveanu, Ioana, Ramon Fauli-Oller, Joel Sandonis, and Juana Santamaria. 2008. "ATM Surcharges: Effects on Deployment and Welfare." http://merlin.fae.ua.es/sandonis/ATMsMay200811.pdf

Cohen, Andrew M., and Michael J. Mazzeo. 2007. "Investment Strategies and Market Structure: An Empirical Analysis of Bank Branching Decisions." http://www.kellogg.northwestern.edu/faculty/mazzeo/htm/branches_cohen_mazzeo1.pdf.

Davis, Peter. 2006. "Spatial Competition in Retail Markets: Movie Theaters." RAND Journal of Economics, 37(4): 964-982.

Donze, Jocelyn, and Isabelle Dubec. 2006. "The role of interchange fees in ATM networks." International Journal of Industrial Organization, 24: 29-43.

Donze, Jocelyn, and Isabelle Dubec. 2008. "Paying for ATM usage: good for consumers, bad for banks?" http://mpra.ub.uni-muenchen.de/10892/1/ATM_TSE.pdf.

European Central Bank. 2001, 2007. "Payment and securities settlements systems in the European Union." Blue book.

Fasig, L. 2001. "This window closed - Fleet touts replacement ATMs as always open." Providence Journal-Bulletin, March 17: Business Section, $1 B$.

Felgran, Steven D. 1984. "Shared ATM Networks: Market Structure and Public Policy." New England Economic Review, Jan/Feb 1984: 23-38.

Gilbert, Richard J., and David M. Newbery. 1982. "Preemptive Patenting and the Persistence of Monopoly. " American Economic Review, 72: 514-526. 
Goolsbee, Austan. 2006. "The Value of Broadband and the Deadweight Loss of Taxing New Technologies." Contributions to Economic Analysis \& Policy, 5(1): Article 8.

Gow, S. H., and Lyn C. Thomas. 1998. "Interchange Fees for Bank ATM Networks." Naval Research Logistics, 45: 407-417.

Gowrisankaran, Gautam, and John Krainer. 2007. "The Welfare Consequences of ATM Surcharges: Evidence from a Structural Entry Model." http://www.u.arizona.edu/ gowrisan/pdf_papers/atm_entry.pdf.

Gresvik, Olaf, and Grete Owre. 2002. "Banks' costs and income in the payment system in 2001." Norges Bank Economic Bulletin, Q4 02: 125-133.

Gronau, Reuben. 1974. "Wage Comparisons: A Selectivity Bias." Journal of Political Economy, 82, pp. 1119-1143.

Guibourg, Gabriela, and Björn Segendorf. 2004. "Do Prices Reflect Costs? A study of the price and cost structure of retail payment services in the Swedish banking sector 2002." Sveriges Riksbank Working Paper Series 172.

Hannan, Timothy H., and Ron Borzekowski. 2007. "Incompatibility and Investment in ATM networks." Review of Network Economics, 6(1): 1-15.

Hannan, Timothy H., Elizabeth K. Kiser, Robin A. Prager, and James J. McAndrews. 2003. "To Surcharge or Not to Surcharge: An Empirical Investigation of ATM pricing." The Review of Economics and Statistics, 85(4): 990-1002.

Hayashi, Fumiko, Richard Sullivan, and Stuart E. Weiner. 2003. "A Guide to the ATM and Debit Card Industry." Federal Reserve Bank of Kansas City. http://www.ffiec.gov/ffiecinfobase/resources/retail/frbguide\%20to\%20the_atm_debit_card_ind.pdf.

Heckman, James J. 1978. "Dummy Endogenous Variables in a Simultaneous Equation System." Econometrica, 46(4): 931-959.

Holmes, Thomas J. 2008. "The Diffusion of Wal-Mart and Economies of Density." NBER Working Paper 13783.

Humphrey, David. 1994. "Delivering Deposit Services: ATMs versus Branches." Federal Reserve Bank of Richmond Economic Quarterly, 80: 59-81. 
Humphrey, David, Magnus Willesson, Göran Bergendahl, and Ted Lindblom. 2003. "Cost Savings from Electronic Payments and ATMs in Europe." Working paper Federal Reserve Bank of Philadelphia 03-16.

Ishii, Joy. 2005. "Interconnection Pricing, Compatibility, and Investment in Network Industries: ATM Networks in the Banking Industry." http://www.econ.yale.edu/seminars/apmicro/am06/ishii-060427.pdf.

Kimball, R. C., and W. T. Gregor. 1995. "How Distribution Is Transforming Retail Banking: Changes Leading Banks Are Making." Journal of Retail Banking Services, 17(3): $1-9$.

Knittel, Christopher R., and Victor Stango. 2006 "Strategic Incompatibility in ATM Markets." NBER Working paper 12604.

Knittel, Christopher R., and Victor Stango. (2008), "Incompatibility, Product Attributes and Consumer Welfare: Evidence from ATMs." The B.E. Journal of Economic Analysis 8 Policy, 8(1) (Advances): Article 1.

Kolesar, Peter, and Edward H. Blum. 1973. "Square Root Laws for Fire Engine Response Distances." Management Science, 19(12): 1368-1378.

Mankiw, N. Gregory, and Michael D. Whinston. 1986. "Free Entry and Social Inefficiency." RAND Journal of Economics, 17: 48-58.

Manuszak, Mark D., and Charles C. Moul. 2008. "Prices and Endogenous Market Structure in Office Supply Superstores." Journal of Industrial Economics, 56: 94-112.

Matutes, Carmen, and A. Jorge Padilla. 1994. "Shared ATM networks and banking competition." European Economic Review, 38: 1113-1138.

Mazzeo, Michael J. 2002. "Competitive Outcomes in Product Differentiated Oligopoly." Review of Economics and Statistics, 84: 716-728.

McAndrews, James J. 1991. "The Evolution of Automatic Teller Machine Networks." Federal Reserve Bank of Philadelphia Business Review, May 1991: 1-22.

McAndrews, James J. 2003. "Automated Teller Machine Network Pricing: A Review of the Literature." Review of Network Economics, 2(2): 146-158.

McAndrews, James J. and Rafael Rob. 1996. "Shared Ownership and Pricing in a Network Switch." International Journal of Industrial Organization. 14: 727-745. 
McFadden, Daniel L., and Kenneth E. Train. 1978. "The Goods/Leisure Tradeoff and Disaggregate Work Trip Mode Choice Models." Transportation Research, 12: 349-353.

Norges Bank. 1999. "Report on Payment Systems 1998." http://www.norgesbank.no/upload/import/english/publications/paymentsystems/1998/payment-1998.pdf

Organisation for Economic Cooperation and Development. 2007. "OECD Communications Outlook 2007."

Organisation for Economic Cooperation and Development. 2008. "Broadband growth and Policies in OECD Countries."

Pakes, Ariel, Jack Porter, Katherine Ho, and Joy Ishii. 2006. "Moment Inequalities and Their Application." http://www.economics.harvard.edu/faculty/pakes/files/Moments_November-06.pdf.

Retail Banking Research Ltd. 1995, 2000, 2008. "ATMs and Cash Dispensers Western Europe."

Retail Banking Research Ltd. 2005. "Study of the Impact of Regulation 2560/2001 on Bank Charges for National Payments." Retail Banking Research London Final Report Project Number MARKT/2004/11/F - LOT 2.

Smith, Howard, and Catherine O'Gorman. 2008. "Efficiency Gain from Ownership Deregulation: Estimates for the Radio Industry." University of Oxford Department of Economics Discussion Paper Series 385.

Snellman, Heli. 2006. "Automated Teller Machine network market structure and cash usage." Bank of Finland Scientific Monographs E38.

Stoneman, Paul. 2002. The Economics of Technological Diffusion. Oxford: Blackwell.

Testaankoop. 2003, "Openingsuren van winkels en openbare diensten." 461: 20-24.

Watson, Randal. Forthcoming. "Product Variety and Competition in the Retail Market for Eyeglasses." Journal of Industrial Economics.

World Payments Report. 2005, 2006. 


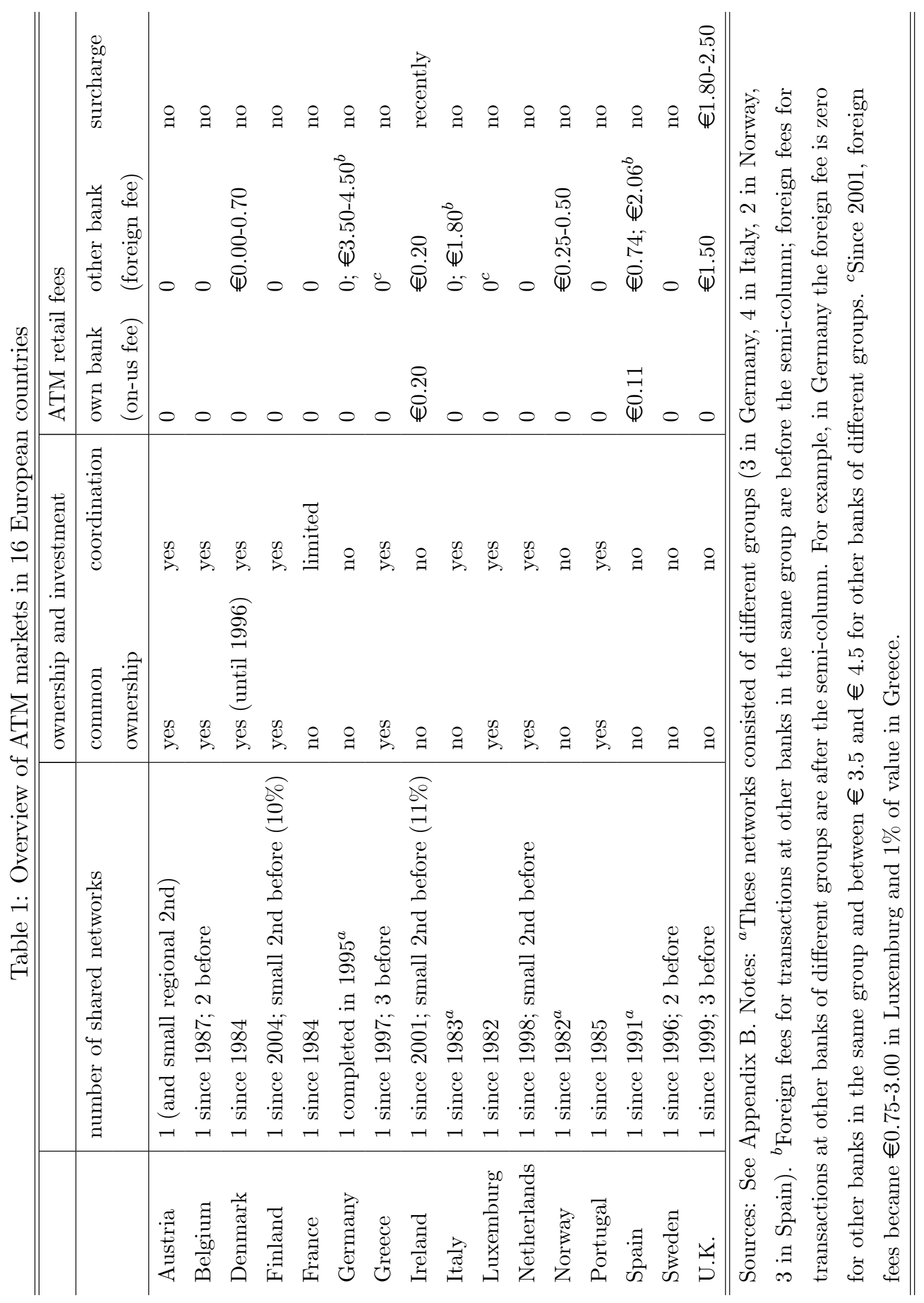


Table 2: Variable description (referring to the sample of markets)

\begin{tabular}{l|l}
\hline \hline ATM withdrawals $\left(Q_{A}\right)$ & monthly per capita number of cash withdrawals at shared ATMs \\
withdrawal value $\left(V_{A} / Q_{A}\right)$ & value per cash withdrawal at shared ATMs \\
number of ATMs $(N)$ & number of shared ATMs \\
number of branches per bank & number of branches per bank \\
population $(L)$ & population \\
surface $(M)$ & surface $\left(\right.$ in $\left.\mathrm{km}^{2}\right)$ \\
enterprises & number of enterprises (divided by 100,000) \\
foreign & fraction of foreigners in the population \\
young & fraction of population under 18 \\
elderly & fraction of population over 65 \\
unemployment rate & unemployment rate \\
Flanders & indicator variable for Dutch-speaking part of Belgium \\
\hline \hline
\end{tabular}

Table 3: Summary statistics

\begin{tabular}{|c|c|c|c|c|}
\hline & \multicolumn{2}{|c|}{ all markets } & \multicolumn{2}{|c|}{$\begin{array}{l}\text { markets with at } \\
\text { least one ATM }\end{array}$} \\
\hline & mean & st. dev. & mean & st. dev. \\
\hline ATM withdrawals $\left(Q_{A}\right)$ & 0.56 & 0.47 & 0.78 & 0.37 \\
\hline withdrawal value $\left(V_{A} / Q_{A}\right)$ & 73.21 & 45.67 & 101.15 & 7.14 \\
\hline number of ATMs $(N)$ & 0.74 & 0.97 & 1.57 & 0.84 \\
\hline number of branches per bank & 0.86 & 0.64 & 1.25 & 0.65 \\
\hline population $(L)$ & 8738 & 7314 & 13445 & 7884 \\
\hline surface $(M)$ & 36.78 & 29.25 & 45.41 & 32.55 \\
\hline enterprises & 0.013 & 0.024 & 0.015 & 0.021 \\
\hline foreign & 0.04 & 0.06 & 0.05 & 0.06 \\
\hline young & 0.22 & 0.02 & 0.21 & 0.02 \\
\hline elderly & 0.16 & 0.02 & 0.16 & 0.02 \\
\hline unemployment rate & 0.03 & 0.02 & 0.03 & 0.02 \\
\hline Flanders & 0.58 & 0.49 & 0.63 & 0.48 \\
\hline number of observations & 659 & & 310 & \\
\hline
\end{tabular}

Notes: For a description of the variables, see Table 2. The means for $Q_{A}$ and $V_{A} / Q_{A}$ are population-weighted. Sources: Banksys, N.I.S., B.V.B. and R.S.Z. 
Table 4: ATM cash withdrawal demand and number of ATMs

\begin{tabular}{c|c|cccc}
\hline \hline & number of & \multicolumn{2}{|c}{ ATM withdrawals } & \multicolumn{2}{c}{ withdrawal value } \\
\cline { 3 - 6 } & observations & mean & st. dev. & mean & st. dev. \\
\hline $\mathrm{N}=0$ & 349 & 0 & 0 & 0 & 0 \\
$\mathrm{~N}=1$ & 185 & 0.63 & 0.31 & 102.22 & 7.38 \\
$\mathrm{~N}=2$ & 90 & 0.83 & 0.37 & 101.27 & 6.97 \\
$\mathrm{~N}=3$ & 23 & 0.96 & 0.41 & 100.35 & 6.67 \\
$\mathrm{~N}=4$ & 9 & 1.01 & 0.32 & 97.08 & 6.47 \\
$\mathrm{~N}=5$ & 2 & 1.13 & 0.35 & 97.65 & 2.68 \\
$\mathrm{~N}=6$ & 1 & 0.74 & & 92.73 & \\
\hline total & 659 & 0.56 & 0.47 & 73.21 & 45.67 \\
\hline \hline
\end{tabular}

Notes: The means for ATM withdrawals and withdrawal value are population-weighted. Source: Banksys.

Table 5: Reduced-form demand regressions

\begin{tabular}{|c|c|c|c|c|}
\hline & param. & st. err. & param. & st. err. \\
\hline & \multicolumn{2}{|c|}{ ATM withdrawals } & \multicolumn{2}{|c|}{ withdrawal value } \\
\hline$(\log )$ number of ATMs $(\ln N)$ & 0.63 & $(0.07)$ & -0.03 & $(0.01)$ \\
\hline (log) number of branches per bank & -0.51 & $(0.07)$ & 0.02 & $(0.01)$ \\
\hline constant & -0.97 & $(0.69)$ & 4.73 & $(0.08)$ \\
\hline enterprises & -0.44 & $(1.32)$ & -0.08 & $(0.14)$ \\
\hline foreign & -0.57 & $(0.51)$ & 0.09 & $(0.06)$ \\
\hline young & -0.29 & $(2.10)$ & -0.50 & $(0.23)$ \\
\hline elderly & 4.84 & $(1.50)$ & 0.03 & $(0.17)$ \\
\hline unemployment rate & -2.63 & $(2.56)$ & -1.44 & $(0.28)$ \\
\hline Flanders & -0.14 & $(0.11)$ & 0.05 & $(0.01)$ \\
\hline $\mathrm{R}^{2}$ & 0.37 & & 0.56 & \\
\hline number of observations & 310 & & 310 & \\
\hline
\end{tabular}

Notes: OLS estimates on cross-section of markets with at least one ATM. Dependent variables are respectively $\log$ of ATM withdrawals $\left(\ln Q_{A}\right)$ and $\log$ of per transaction withdrawal value $\left(\ln \left(V_{A} / Q_{A}\right)\right)$. 
Table 6: Parameter estimates and predictions from demand model only

\begin{tabular}{|c|c|c|c|c|}
\hline & param. & st. err. & param. & st. err. \\
\hline & \multicolumn{4}{|c|}{ demand equation (11) } \\
\hline$\alpha$ & 6.18 & $(1.05)$ & 5.47 & $(1.19)$ \\
\hline$v_{B}-v_{A}$ & -0.59 & $(0.38)$ & -0.75 & $(0.48)$ \\
\hline constant & 0.25 & $(0.12)$ & 0.08 & $(0.58)$ \\
\hline enterprises & & & 0.08 & $(0.83)$ \\
\hline foreign & & & 0.13 & $(0.33)$ \\
\hline young & & & -1.07 & $(1.68)$ \\
\hline elderly & & & 3.97 & $(1.26)$ \\
\hline unemployment rate & & & -3.70 & $(2.26)$ \\
\hline Flanders & & & -0.33 & $(0.08)$ \\
\hline \multirow[t]{2}{*}{$\sigma_{1}$} & 0.39 & $(0.01)$ & 0.36 & $(0.01)$ \\
\hline & \multicolumn{4}{|c|}{ implied demand predictions } \\
\hline cash withdrawals $(\bar{Q})$ & 1.28 & $(0.15)$ & 1.21 & $(0.17)$ \\
\hline share of ATMs $\left(s_{A}\right)$ & 0.56 & $(0.07)$ & 0.60 & $(0.09)$ \\
\hline $\operatorname{ATM}$ elasticity $\left(E_{A}^{N}\right)$ & 1.09 & $(0.09)$ & 0.89 & $(0.09)$ \\
\hline price elasticity $\left(E_{A}^{P}\right)$ & -2.18 & $(0.18)$ & -1.77 & $(0.17)$ \\
\hline number of observations & 310 & & 310 & \\
\hline
\end{tabular}

Notes: Implied demand predictions are at sample means. 
Table 7: Parameter estimates and predictions from simultaneous demand and entry model

\begin{tabular}{|c|c|c|c|c|}
\hline & param. & st. err. & param. & st. err. \\
\hline & \multicolumn{4}{|c|}{ demand equation (11) } \\
\hline$\alpha$ & 2.30 & $(0.22)$ & 2.18 & $(0.22)$ \\
\hline$v_{B}-v_{A}$ & 0.51 & $(0.25)$ & 0.65 & $(0.27)$ \\
\hline constant & 0.54 & $(0.17)$ & 0.28 & $(0.56)$ \\
\hline enterprises & & & -1.43 & $(0.85)$ \\
\hline foreign & & & -0.11 & $(0.29)$ \\
\hline young & & & -0.75 & $(1.68)$ \\
\hline elderly & & & 4.31 & $(1.19)$ \\
\hline unemployment rate & & & -0.23 & $(2.32)$ \\
\hline Flanders & & & -0.21 & $(0.09)$ \\
\hline \multirow[t]{2}{*}{$\sigma_{1}$} & 0.44 & $(0.02)$ & 0.40 & $(0.02)$ \\
\hline & \multicolumn{4}{|c|}{ implied demand predictions } \\
\hline cash withdrawals $(\bar{Q})$ & 1.71 & $(0.28)$ & 1.93 & $(0.35)$ \\
\hline share of ATMs $\left(s_{A}\right)$ & 0.35 & $(0.05)$ & 0.32 & $(0.06)$ \\
\hline $\operatorname{ATM}$ elasticity $\left(E_{A}^{N}\right)$ & 0.65 & $(0.02)$ & 0.65 & $(0.03)$ \\
\hline \multirow[t]{2}{*}{ price elasticity $\left(E_{A}^{P}\right)$} & -1.29 & $(0.04)$ & -1.29 & $(0.05)$ \\
\hline & \multicolumn{4}{|c|}{ investment equation (16)-(17) } \\
\hline constant & 8.26 & $(0.04)$ & 9.22 & $(0.69)$ \\
\hline enterprises & & & -0.23 & $(0.96)$ \\
\hline foreign & & & -1.85 & $(0.49)$ \\
\hline young & & & 1.14 & $(2.08)$ \\
\hline elderly & & & -5.13 & $(1.60)$ \\
\hline unemployment rate & & & -4.68 & $(2.50)$ \\
\hline Flanders & & & -0.23 & $(0.10)$ \\
\hline$\sigma_{2}$ & 0.70 & $(0.03)$ & 0.61 & $(0.03)$ \\
\hline \multirow[t]{2}{*}{$\sigma_{12}$} & -0.22 & $(0.03)$ & -0.17 & $(0.02)$ \\
\hline & \multicolumn{4}{|c|}{ implied cost predictions } \\
\hline$F /\left(c_{B}-c_{A}\right)$ & 3876 & $(164)$ & 3932 & $(158)$ \\
\hline$R^{2}$ & 0.60 & & 0.65 & \\
\hline number of observations & 659 & & 659 & \\
\hline
\end{tabular}


Table 8: Policy counterfactuals

\begin{tabular}{|c|c|c|c|c|}
\hline & status quo & first-best & bsidies-o & fees-only \\
\hline & \multicolumn{4}{|c|}{ optimal subsidies and fees } \\
\hline \multirow[t]{2}{*}{ average subsidy per ATM $S$} & 0 & 2236 & 1545 & 0 \\
\hline & & $(2.60)$ & $(13.05)$ & \\
\hline \multirow[t]{3}{*}{ average fee $t_{B}-t_{A}$} & 0 & 0.62 & 0 & 0.47 \\
\hline & & $(0.01)$ & & $(0.01)$ \\
\hline & \multicolumn{4}{|c|}{ ATM investment and demand } \\
\hline \multirow[t]{2}{*}{ total number of ATMs } & 490 & 1018 & 1022 & 463 \\
\hline & $(18.59)$ & $(20.41)$ & $(22.20)$ & $(14.84)$ \\
\hline \multirow[t]{2}{*}{ total number of markets without ATM } & 330 & 114 & 148 & 312 \\
\hline & $(10.18)$ & $(7.08)$ & $(7.67)$ & $(10.51)$ \\
\hline \multirow[t]{2}{*}{ average share of ATM cash withdrawals } & 0.25 & 0.66 & 0.38 & 0.39 \\
\hline & $(0.01)$ & $(0.01)$ & $(0.00)$ & $(0.01)$ \\
\hline \multirow[t]{3}{*}{ average number of ATM cash withdrawals } & 0.59 & 1.42 & 0.84 & 0.89 \\
\hline & $(0.03)$ & $(0.04)$ & $(0.03)$ & $(0.04)$ \\
\hline & \multicolumn{4}{|c|}{ welfare (in millions of euro) } \\
\hline \multirow[t]{2}{*}{ change in producer surplus } & 0 & 6.40 & 1.14 & 4.06 \\
\hline & & $(0.20)$ & $(0.02)$ & $(0.17)$ \\
\hline \multirow[t]{2}{*}{ change in consumer surplus } & 0 & -1.97 & 1.03 & -2.94 \\
\hline & & $(0.08)$ & $(0.04)$ & $(0.10)$ \\
\hline \multirow[t]{2}{*}{ change in government revenues } & 0 & -2.27 & -1.58 & 0 \\
\hline & & $(0.05)$ & $(0.03)$ & \\
\hline \multirow[t]{2}{*}{ change in total welfare } & 0 & 2.16 & 0.59 & 1.12 \\
\hline & & $(0.10)$ & $(0.03)$ & $(0.08)$ \\
\hline
\end{tabular}

Notes: Number of observations is 659 markets. 100 simulation draws per market. Standard errors are in parentheses. Travel cost per unit of distance $k=€ 0.25$, ATM fixed costs $F=€ 2300$, as discussed in the text. 
Table 9: Square root travel distance measure versus actual average travel distance

\begin{tabular}{l|lll|cccc}
\hline \hline & \multicolumn{3}{|c|}{ average distances } & \multicolumn{4}{c}{ average distance regression } \\
\hline$x$ & sq. rt. & actual & corr. & $\varphi_{0}$ & $\varphi_{1}$ & $\varphi_{2}$ & $R^{2}$ \\
\hline$N$ & 2.71 & 2.00 & 0.75 & $0.38^{*}$ & 0.48 & $-0.34^{*}$ & 0.61 \\
$B^{1}$ & 2.65 & 1.78 & 0.75 & $0.38^{*}$ & $0.46^{*}$ & -0.52 & 0.60 \\
$B^{2}$ & 2.71 & 1.74 & 0.71 & $0.41^{*}$ & $0.42^{*}$ & -0.44 & 0.56 \\
$B^{3}$ & 2.82 & 1.91 & 0.76 & $0.34^{*}$ & 0.49 & -0.52 & 0.62 \\
$B^{4}$ & 2.42 & 1.58 & 0.73 & $0.38^{*}$ & $0.45^{*}$ & -0.48 & 0.58 \\
$B^{5}$ & 2.79 & 1.93 & 0.74 & $0.32^{*}$ & 0.51 & -0.50 & 0.64 \\
$B^{6}$ & 2.74 & 1.85 & 0.73 & $0.35^{*}$ & 0.48 & -0.50 & 0.59 \\
$B^{7}$ & 2.45 & 1.63 & 0.72 & $0.34^{*}$ & 0.48 & -0.49 & 0.55 \\
$B^{8}$ & 3.04 & 2.21 & 0.61 & $0.38^{*}$ & 0.46 & -0.35 & 0.47 \\
\hline \hline
\end{tabular}

Notes: Column 1 provides the distance to the nearest ATM $(N)$ and branch of bank $i\left(B^{i}\right)$, implied by the square root measures of our base model, $d(N)$ and $d\left(B^{i}\right)$ (averaged across our sample of markets). Column 2 provides the actual average distance based on consumer, ATM and branch locations, $\bar{d}_{A}$ and $\bar{d}_{B}^{i}$ (averaged across markets). Column 3 shows the correlation between the square root measure and the actual average distance measure. Columns 4-7 present the results from a cross-market regression of the log of actual average distance on the log of market surface and log of number of locations. An asterix indicates that the parameters differ significantly from the square root proxy (where $\varphi_{0}=\frac{1}{2}, \varphi_{1}=\frac{1}{2}$ and $\varphi_{2}=-\frac{1}{2}$ as discussed in the text). 
Table 10: Parameter estimates and predictions from simultaneous demand and entry model: extensions

\begin{tabular}{|c|c|c|c|c|c|c|}
\hline & \multicolumn{6}{|c|}{ param. st. err. param. st. err. param. } \\
\hline & \multicolumn{2}{|c|}{ gen. distance } & \multicolumn{2}{|c|}{ semilog } & \multicolumn{2}{|c|}{ ec. of density } \\
\hline & \multicolumn{6}{|c|}{ demand equation (11) } \\
\hline$\alpha$ & 4.29 & $(0.43)$ & 1.33 & $(0.06)$ & 1.94 & $(0.22)$ \\
\hline$v_{B}-v_{A}$ & 0.66 & $(0.30)$ & 1.17 & - & -0.18 & $(0.42)$ \\
\hline constant & 0.53 & $(0.56)$ & 0.31 & $(0.55)$ & -0.08 & $(0.57)$ \\
\hline enterprises & -1.51 & $(0.85)$ & -1.64 & $(0.83)$ & -1.69 & $(0.88)$ \\
\hline foreign & -0.09 & $(0.29)$ & -0.17 & $(0.29)$ & -0.07 & $(0.30)$ \\
\hline young & -1.13 & $(1.66)$ & -0.71 & $(1.70)$ & -1.57 & $(1.74)$ \\
\hline elderly & 3.80 & $(1.19)$ & 4.46 & $(1.19)$ & 4.57 & $(1.23)$ \\
\hline unemployment rate & -0.05 & $(2.26)$ & 0.19 & $(2.33)$ & 0.85 & $(2.34)$ \\
\hline Flanders & -0.19 & $(0.08)$ & -0.21 & $(0.09)$ & -0.23 & $(0.09)$ \\
\hline \multirow[t]{2}{*}{$\sigma_{1}$} & 0.39 & $(0.02)$ & 0.41 & $(0.02)$ & 0.41 & $(0.02)$ \\
\hline & \multicolumn{6}{|c|}{ implied demand predictions } \\
\hline cash withdrawals $(\bar{Q})$ & 2.16 & $(0.42)$ & 2.08 & $(0.07)$ & 1.21 & $(0.25)$ \\
\hline share of ATMs $\left(s_{A}\right)$ & 0.30 & $(0.06)$ & 0.29 & $(0.00)$ & 0.52 & $(0.10)$ \\
\hline $\operatorname{ATM}$ elasticity $\left(E_{A}^{N}\right)$ & 0.58 & $(0.03)$ & 0.59 & $(0.03)$ & 0.41 & $(0.07)$ \\
\hline \multirow[t]{2}{*}{ price elasticity $\left(E_{A}^{P}\right)$} & -1.70 & $(0.07)$ & -1.18 & $(0.06)$ & -0.81 & $(0.14)$ \\
\hline & \multicolumn{6}{|c|}{ investment equation (16)-(17) } \\
\hline constant & 9.39 & $(0.65)$ & 9.20 & $(0.66)$ & 9.56 & $(0.64)$ \\
\hline enterprises & -0.37 & $(0.93)$ & -0.46 & $(0.91)$ & -0.46 & $(0.90)$ \\
\hline foreign & -1.71 & $(0.47)$ & -2.03 & $(0.47)$ & -1.68 & $(0.47)$ \\
\hline young & 0.29 & $(1.97)$ & 1.04 & $(1.99)$ & -0.72 & $(1.97)$ \\
\hline elderly & -5.21 & $(1.51)$ & -4.80 & $(1.53)$ & -5.07 & $(1.46)$ \\
\hline unemployment rate & -3.75 & $(2.42)$ & -4.21 & $(2.41)$ & -2.38 & 2.42) \\
\hline Flanders & -0.19 & $(0.10)$ & -0.26 & $(0.10)$ & -0.15 & $(0.09)$ \\
\hline ec. of density $(\lambda)$ & 0 & & 0 & & -0.36 & $(0.10)$ \\
\hline$\sigma_{2}$ & 0.57 & $(0.03)$ & 0.61 & $(0.03)$ & 0.59 & $(0.03)$ \\
\hline \multirow[t]{2}{*}{$\sigma_{12}$} & -0.15 & $(0.02)$ & -0.18 & $(0.02)$ & -0.18 & $(0.02)$ \\
\hline & \multicolumn{6}{|c|}{ implied cost predictions } \\
\hline$F /\left(c_{B}-c_{A}\right)$ for $N=1$ & 4035 & $(164)$ & 3894 & $(164)$ & 4176 & $(157)$ \\
\hline$F /\left(c_{B}-c_{A}\right)$ for $N=2$ & 4035 & $(164)$ & 3894 & $(164)$ & 3264 & $(123)$ \\
\hline$R^{2}$ & 0.65 & & 0.64 & & 0.65 & \\
\hline number of observations & 659 & & 659 & & 659 & \\
\hline
\end{tabular}

Notes: Implied demand and cost predictions are at sample means. In the semilog specification, the value of $v_{B}-v_{A}$ is fixed such that the predicted $\bar{Q}=2.07$ for the representative market. 


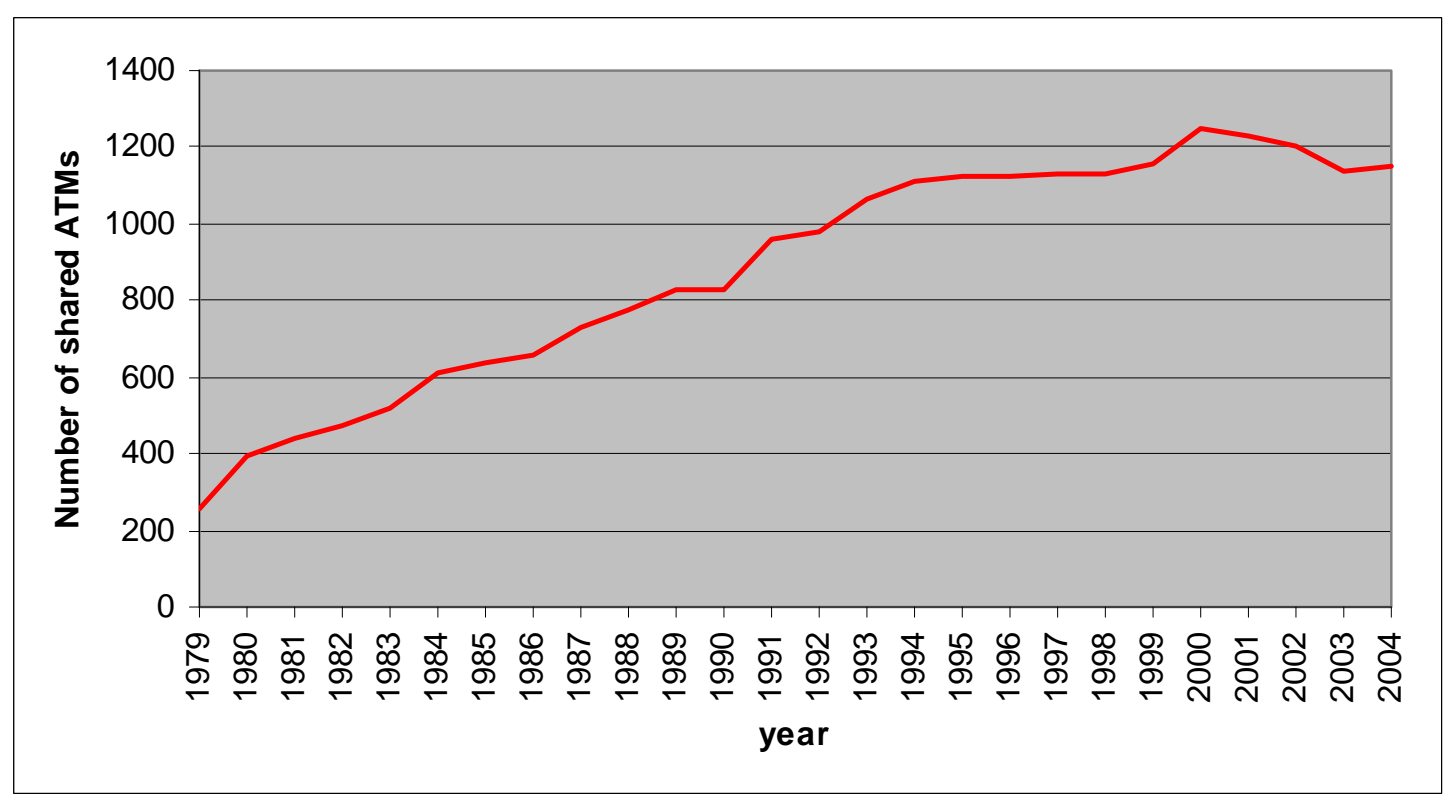

Figure 1: Evolution of the shared ATM network in Belgium (1979-2004) 


\section{Appendix A: Sensitivity analysis}

Table A1: Parameter estimates and predictions from demand model only: full sample of markets

\begin{tabular}{l|rrrr}
\hline \hline & param. & st. err. & param. & st. err. \\
\hline & \multicolumn{4}{|c}{ demand equation (11) } \\
\hline$a$ & 6.36 & $(0.99)$ & 5.50 & $(1.11)$ \\
$v_{B}-v_{A}$ & -0.30 & $(0.33)$ & -0.48 & $(0.44)$ \\
constant & 0.39 & $(0.12)$ & 1.65 & $(0.38)$ \\
enterprises & & & 0.75 & $(0.37)$ \\
foreign & & & 0.62 & $(0.33)$ \\
young & & & -5.16 & $(0.94)$ \\
elderly & & & 0.33 & $(1.02)$ \\
unemployment rate & & & -3.85 & $(1.72)$ \\
Flanders & & & -0.38 & $(0.07)$ \\
$\sigma_{1}$ & 0.44 & $(0.01)$ & 0.42 & $(0.01)$ \\
\hline & implied demand predictions \\
\hline cash withdrawals $(\bar{Q})$ & 1.47 & $(0.18)$ & 1.35 & $(0.20)$ \\
share of ATMs $\left(s_{A}\right)$ & 0.62 & $(0.07)$ & 0.66 & $(0.10)$ \\
ATM elasticity $\left(E_{A}^{N}\right)$ & 0.73 & $(0.07)$ & 0.58 & $(0.07)$ \\
price elasticity $\left(E_{A}^{P}\right)$ & -1.46 & $(0.14)$ & -1.16 & $(0.14)$ \\
\hline number of observations & 467 & \multicolumn{3}{c}{467} \\
\hline \hline
\end{tabular}

Notes: Implied demand predictions are at sample means. 
Table A2: Parameter estimates and predictions from simultaneous demand and entry model: full sample of markets

\begin{tabular}{|c|c|c|c|c|}
\hline \multirow[b]{3}{*}{$\alpha$} & \multirow{2}{*}{\multicolumn{4}{|c|}{$\frac{\text { param. st. err. param. st. err }}{\text { demand equation }(11)}$}} \\
\hline & & & & \\
\hline & \multirow{3}{*}{$\begin{array}{r}2.99 \\
-0.08 \\
0.25\end{array}$} & \multirow{2}{*}{$\begin{array}{l}(0.27) \\
(0.20)\end{array}$} & \multirow{2}{*}{$\begin{array}{l}2.70 \\
0.15\end{array}$} & $(0.24)$ \\
\hline$v_{B}-v_{A}$ & & & & $(0.21)$ \\
\hline constant & & $(0.10)$ & 1.49 & $(0.41)$ \\
\hline enterprises & & & 0.93 & $(0.40)$ \\
\hline foreign & & & 0.69 & $(0.32)$ \\
\hline young & & & -5.55 & $(1.03)$ \\
\hline elderly & & & 1.39 & $(1.06)$ \\
\hline unemployment rate & & & -1.43 & $(1.87)$ \\
\hline Flanders & & & -0.30 & $(0.08)$ \\
\hline \multirow[t]{2}{*}{$\sigma_{1}$} & 0.51 & $(0.01)$ & 0.47 & $(0.01)$ \\
\hline & \multicolumn{4}{|c|}{ implied demand predictions } \\
\hline cash withdrawals $(\bar{Q})$ & 1.28 & $(0.13)$ & 1.45 & $(0.17)$ \\
\hline share of ATMs $\left(s_{A}\right)$ & 0.55 & $(0.05)$ & 0.49 & $(0.05)$ \\
\hline ATM elasticity $\left(E_{A}^{N}\right)$ & 0.43 & $(0.01)$ & 0.44 & $(0.01)$ \\
\hline \multirow[t]{2}{*}{ price elasticity $\left(E_{A}^{P}\right)$} & -0.86 & $(0.02)$ & -0.88 & $(0.02)$ \\
\hline & \multicolumn{4}{|c|}{ investment equation (16)-(17) } \\
\hline constant & 8.10 & $(0.04)$ & 9.67 & $(0.55)$ \\
\hline enterprises & & & -1.77 & $(0.57)$ \\
\hline foreign & & & -2.06 & $(0.38)$ \\
\hline young & & & 1.38 & $(1.65)$ \\
\hline elderly & & & -8.25 & $(1.31)$ \\
\hline unemployment rate & & & -5.54 & $(1.91)$ \\
\hline Flanders & & & -0.24 & $(0.09)$ \\
\hline$\sigma_{2}$ & 0.99 & $(0.04)$ & 0.80 & $(0.03)$ \\
\hline \multirow[t]{2}{*}{$\sigma_{12}$} & -0.39 & $(0.03)$ & -0.28 & $(0.03)$ \\
\hline & \multicolumn{4}{|c|}{ implied cost predictions } \\
\hline$F /\left(c_{B}-c_{A}\right)$ & 3284 & $(134)$ & 3337 & $(126)$ \\
\hline$R^{2}$ & 0.56 & & 0.62 & \\
\hline number of observations & 842 & & 842 & \\
\hline \multicolumn{5}{|c|}{$\begin{array}{l}\text { Notes: Implied demand and cost predictions are at sample } \\
\text { means. }\end{array}$} \\
\hline
\end{tabular}


Table A3: Policy counterfactuals: alternative cost per unit of distance

\begin{tabular}{|c|c|c|c|c|}
\hline & status quo & first best & subsidies-only & fees-only \\
\hline & \multicolumn{4}{|c|}{ optimal subsidies and fees } \\
\hline average subsidy per ATM $S$ & 0 & $\begin{array}{c}2243 \\
(1.18)\end{array}$ & $\begin{array}{c}1208 \\
(17.39)\end{array}$ & 0 \\
\hline \multirow[t]{2}{*}{ average fee $t_{B}-t_{A}$} & 0 & $\begin{array}{c}0.62 \\
(0.01)\end{array}$ & 0 & $\begin{array}{c}0.53 \\
(0.01)\end{array}$ \\
\hline & \multicolumn{4}{|c|}{ ATM investment and demand } \\
\hline total number of ATMs & $\begin{array}{c}490 \\
(18.59)\end{array}$ & $\begin{array}{c}700 \\
(13.47)\end{array}$ & $\begin{array}{c}711 \\
(20.77)\end{array}$ & $\begin{array}{c}409 \\
(11.81)\end{array}$ \\
\hline total number of markets without ATM & $\begin{array}{c}330 \\
(10.18)\end{array}$ & $\begin{array}{c}131 \\
(8.21)\end{array}$ & $\begin{array}{c}234 \\
(10.09)\end{array}$ & $\begin{array}{c}284 \\
(10.15)\end{array}$ \\
\hline average share of ATM cash withdrawals & $\begin{array}{c}0.25 \\
(0.01)\end{array}$ & $\begin{array}{c}0.83 \\
(0.01)\end{array}$ & $\begin{array}{c}0.32 \\
(0.01)\end{array}$ & $\begin{array}{c}0.62 \\
(0.01)\end{array}$ \\
\hline \multirow[t]{2}{*}{ average number of ATM cash withdrawals } & $\begin{array}{c}0.59 \\
(0.03) \\
\end{array}$ & $\begin{array}{c}1.75 \\
(0.05) \\
\end{array}$ & $\begin{array}{c}0.72 \\
(0.03) \\
\end{array}$ & $\begin{array}{c}1.36 \\
(0.05) \\
\end{array}$ \\
\hline & \multicolumn{4}{|c|}{ welfare (in millions of euro) } \\
\hline change in producer surplus & 0 & $\begin{array}{c}6.54 \\
(0.20)\end{array}$ & $\begin{array}{c}0.76 \\
(0.02)\end{array}$ & $\begin{array}{c}5.29 \\
(0.19)\end{array}$ \\
\hline change in consumer surplus & 0 & $\begin{array}{l}-1.96 \\
(0.05)\end{array}$ & $\begin{array}{c}0.21 \\
(0.01)\end{array}$ & $\begin{array}{l}-2.74 \\
(0.07)\end{array}$ \\
\hline change in government revenues & 0 & $\begin{array}{l}-1.57 \\
(0.03)\end{array}$ & $\begin{array}{l}-0.86 \\
(0.02)\end{array}$ & 0 \\
\hline change in total welfare & 0 & $\begin{array}{c}3.02 \\
(0.15)\end{array}$ & $\begin{array}{c}0.11 \\
(0.01)\end{array}$ & $\begin{array}{c}2.55 \\
(0.14)\end{array}$ \\
\hline
\end{tabular}

Notes: Number of observations is 842 markets. 100 simulations draws per market. Standard errors are in parentheses. Cost per unit of distance $k=€ 0.10$, ATM fixed costs $F=€ 2300$, as discussed in the text. 


\section{Appendix B: ATM networks in European countries}

This Appendix reviews the ATM networks in 16 European countries. For each country we first review the ATM network developments (number of networks, ownership and coordination), primarily based on periodic reports by RBR (1995, 2000, 2008). We then summarize retail fee practices, mainly based on RBR's (2005) report for the European Commission. ${ }^{44}$ In addition to these sources, we also used the period reports of B.I.S. (1999, 2003), the ECB (2001, 2007), and Snellman's (2006) international review based on person-to-person information from central banks and banking associations.

Based on this review we constructed Table 1 and we refer to the main text for a summary discussion.

Austria In 1978, the four largest banks started the mutually owned company, GABE, to develop a national ATM network, Bancomat. Other banks were allowed to join, so that almost all banks in Austria now jointly own GABE. (In 1993 GABE was changed into a new company APSS, and in 2007 it became PayLife bank after the take-over by First Data.) For a long time GABE coordinated the ATM investment decisions of the Bancomat network. Nowadays, banks make their own investment decisions, but purchases are still coordinated. There was a second, smaller and only regional network, Spardat, consisting of mainly savings banks. This network also coordinated its investment decisions.

ATM withdrawals have been free of charge both for withdrawals at the own bank's ATMs and at the ATMs of other banks in the same network.

Belgium Two ATM networks, Bancontact and Mr Cash, were introduced at the end of the 1970s. The networks were made compatible in 1987 and they merged to form one entity Banksys in 1989, under common ownership of the banks.

There have been no retail fees for cash withdrawals.

Denmark In 1975 banks agreed not to install ATMs. In 1981, however, they changed strategy and set up a mutually owned network, Kontanten, which took off in 1984 . The network initially coordinated the investment decisions. In 1993, the individual banks took control of the investment decisions, subject to quota decided by the joint network.

\footnotetext{
${ }^{44}$ Unless otherwise indicated, our description of fees refers to 2001 ; it is reasonable to assume that fees before were either the same or lower.
} 
Customers pay a fee of $€ 0.70$ for withdrawals outside opening hours or at other banks.

Finland Initially two networks developed. The commercial banks created the first network in the early 80s, POLT. In 1994 this network was sold to a new company, Automatia, under joint ownership of the three largest banks. This move led to a cut-back in the number of ATMs. The savings banks created a parallel second network under their joint ownership in 1984, Samlink. This network was much smaller (about 10\%); it was gradually integrated in Automatia and eventually ceased to exist in 2004.

Until 2002, there were no charges for ATM cash withdrawals within or between the two networks. In 2002, banks started to charge fees between $€ 0.50-1.28$ for withdrawals between the two networks (but this was no longer relevant from 2004 when Samlink disappeared).

France During the 1970s banks started to develop their own networks with a complicated pattern of agreements, the largest networks being Carte Blue (commercial banks) and Carte Verte (Credit Agricole and Credit Mutuel). By 1986 a national shared network CB (Carte Bancaire) was created. There was no common ownership. The individual banks retained control of their installation plans, but CB had some coordinating role during periodic meetings.

There were generally no charges on ATM withdrawals, with the exception of BNPParibas, who charged $€ 0.78$ after six free transactions per month.

Germany Banks initially invested in their own networks, but then developed a shared national network, the GAA pool. In 1982 about 30\% of the ATMs and by 1995 all of the ATMs belonged to the pool. Within the pool, three main banking groups emerged: the commercial, savings and co-operative banks.

Banks do not charge fees for cash withdrawals at ATMs within the same banking group (regardless of the bank), but charge high fees of about $€ 3.5-4.5$ for cash withdrawals at ATMs of other banking groups.

Greece ATMs developed slowly in part because salaries were commonly paid in cash. There were initially three competing networks ("reciprocity agreements"). In 1997 a joint network, DIASNET, was created, which was jointly owned by 39 banks.

Up to 2001 there were no retail fees for ATM cash withdrawals. Since 2001, a 1\% foreign fee for cash withdrawals at other banks was introduced. 
Ireland Banks initially developed their own networks. In 1984, three large banks set up a shared network, IBN. Several other banks joined that network in the late 1980s. There was another, much smaller network, Cashere, established in 1991 by four building societies. Even at its peak it comprised fewer than 100 machines (about 11\% of total). After a merger between a bank and one of the Cashere members in 2001, the network was dissolved (with some machines integrated in IBN and others removed).

There have always been charges for ATM cash withdrawal services (about $€ 0.20$ on average), regardless of whether the transaction takes place at the own bank or at other banks. Most recently, independent ATM deployers wanted to install ATMs based on surcharging; after heavy consumer protest, a regulation was introduced stipulating that the independent deployers should first establish a relationship with an Irish bank.

Italy Banks initially developed their own networks, in part to increase geographic coverage because of branch entry restrictions at that time. In 1983, the Italian banking association introduced the shared network Bancomat. The network consisted of four different processing centers, some of which merged in later years. Banks were allowed to deploy ATMs according to a quota system, based on a bank's market share of deposits.

There are no retail fees for cash withdrawals at banks within the same processing center, but there are foreign fees of on average $€ 1.8$ for transactions across processing centers.

Luxemburg The shared network, Bancomat, was introduced in 1982, to avoid competitive installations. In 1985 CETREL was formed, owned by eleven banks. Since 1989 CETREL has been responsible for the management of the Bancomat network.

Retail fees for cash withdrawals were only introduced in 2002, and only for transactions at other banks. These foreign fees ranged between $€ 0.75-3.00$, often after a minimum of free monthly transactions.

Netherlands Banks started to install ATMs slowly, but had increased interest in the mid 1980s because of high labour costs and branch maintenance costs. A first shared network, Interpay, emerged in 1989 and was jointly owned by the eight largest banks. The second network was operated by the Postbank, which later merged with the bank ING. Both networks became fully compatible in 1998 under the name Interpay Nederland.

Retail fees have been zero, but recently some independent ATM deployers entered and started to charge surcharges of $€ 2$ per transaction. 
Norway A shared network, MiniBank, was introduced in 1982. The network consisted of three and subsequently two data centers, owned by groups of savings and/or commercial banks.

Retail fees for ATM cash withdrawals have been free at the customers' own bank ATMs during business hours. In 1999, there was a charge per transaction for withdrawals at own bank's ATMs outside business hours of about $€ 0.4$; other bank's ATMs during business hours of about $€ 0.25$ and outside business hours of about $€ 0.5$ (Norges Bank (1999), p. 26).

Portugal There is a single shared ATM network, Multibanco, since 1985. It is operated by SIBS and under joined ownership of the member banks. SIBS decides on the number of ATMs and allocates ATMs according to criteria such as their branch and deposit market share.

There are no retail fees for ATM transactions.

Spain There were initially three networks, ServiRed, Red 6000 and Telebanco 4B; each network was managed and co-owned by different banks. The networks became interoperable in 1991, but continued to be managed as separate entities.

In 2001 retail fees were $€ 0.11$ for cash withdrawals at the own bank; $€ 0.74$ for withdrawals at other banks in the own network; and $€ 2.06$ for withdrawals at banks of different networks.

Sweden Sweden was the first country in Europe to introduce ATMs on a large scale. Two networks emerged in the late seventies. The first network, Minuten, consisted of savings banks and had the objective to rationalize branch operations and reduce pressure on tellers. The second network was Bancomat, and consisted of commercial, state-owned and cooperative banks. Both networks became interoperable in 1996.

Banks do not charge retail fees for ATM cash withdrawals within the same network. Recently, two independent ATM deployers entered and impose surcharges on their ATMs.

United Kingdom During the 1980s banks developed three different shared networks: MINT, the "group of four" and LINK. As one of the last countries in Europe, these networks became shared in 1999.

There were no retail fees for ATM withdrawals at the own bank, but fees of about $€ 1.50$ for withdrawals at other banks. Furthermore, independent ATM deployers imposed surcharges of between $€ 1.80-2.50$ 